\title{
Evolution of Fe species during the synthesis of over-exchanged Fe/ZSM5 obtained by chemical vapor deposition of $\mathrm{FeCl}_{3}$
}

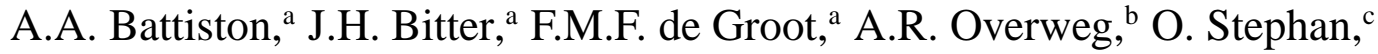 \\ J.A. van Bokhoven, ${ }^{\mathrm{a}, 1}$ P.J. Kooyman, ${ }^{\mathrm{d}}$ C. van der Spek, ${ }^{\mathrm{a}}$ \\ G. Vankó, ${ }^{\mathrm{e}}$ and D.C. Koningsberger ${ }^{\mathrm{a}, *}$ \\ a Department of Inorganic Chemistry and Catalysis, Debye Institute, Utrecht University, Sorbonnelaan 16, 3584 CA Utrecht, The Netherlands \\ b Interfacultair Reactor Instituut, Delft University of Technology, Mekelweg 15, 2629 JB Delft, The Netherlands \\ ${ }^{\mathrm{c}}$ Laboratoire de Physique des Solides, Bâtiment 510, CNRS UMR 8502, F91405 Orsay, France \\ ${ }^{\mathrm{d}}$ National Centre for High Resolution Electron Microscopy, Rotterdamseweg 137, 2628 AL Delft, The Netherlands \\ e European Synchrotron Radiation Facility, BP 220, F-38043 Grenoble cedex, France
}

Received 15 July 2002; revised 7 October 2002; accepted 9 October 2002

\begin{abstract}
The evolution of iron in over-exchanged Fe/ZSM5 prepared via chemical vapor deposition of $\mathrm{FeCl}_{3}$ was studied at each stage of the synthesis. Different characterization techniques (EXAFS, HR-XANES, ${ }^{57}$ Fe Mössbauer spectroscopy, ${ }^{27}$ Al NMR, EELS, HR-TEM, XRD, $\mathrm{N}_{2}$ physisorption, and FTIR spectroscopy) were applied in order to correlate the changes occurring in the local environment of the Fe atoms with migration and aggregation phenomena of iron at micro- and macroscopic scale. Mononuclear isolated $\mathrm{Fe}_{-}$-species are formed upon $\mathrm{FeCl}_{3}$ sublimation, which are transformed into binuclear Fe-complexes during washing. During calcination, iron detached from the Brønsted sites migrates to the external surface of the zeolite, finally leading to significant agglomeration. Nevertheless, agglomeration of Fe can be strongly suppressed by adequately tuning the conditions of the calcination.
\end{abstract}

(c) 2002 Elsevier Science (USA). All rights reserved.

Keywords: Fe/ZSM5; Binuclear; Iron; Synthesis; Evolution; Calcination

\section{Introduction}

Iron loaded zeolites have recently attracted renewed attention due to their outstanding catalytic properties [1-14]. In particular, over-exchanged Fe/ZSM5 (Fe/Al molar ratio $>0.5$ ) obtained through the chemical vapor deposition (CVD) of anhydrous iron trichloride has been reported to be very efficient in the selective catalytic reduction of nitrogen oxides using HydroCarbons (HC-SCR). The extremely high activity of this material has been demonstrated in a wide

\footnotetext{
* Corresponding author.

E-mail address: D.C.Koningsberger@chem.uu.nl (D.C. Koningsberger).

1 Present address: Laboratory for Technical Chemistry, Swiss Federal Institute of Technology (ETH), Universitätstrasse 6, Zürich, CH-8092 Switzerland.
}

oxygen concentration window $(2-10 \%)$ and in the presence of water $(10 \%)$ when using isobutane as the reductant $[1,2]$. A similar performance has been achieved when using $n$-butane or propane [3]. Furthermore, high activity on $\mathrm{Fe} / \mathrm{ZSM} 5$ obtained through CVD of $\mathrm{FeCl}_{3}$ has been claimed also for the conventional selective catalytic reduction of NO using ammonia [4-6] and for the catalytic decomposition of $\mathrm{N}_{2} \mathrm{O}$ [7].

Besides $\mathrm{CVD}$ of anhydrous $\mathrm{FeCl}_{3}$, alternative methods with the aim of synthesizing highly iron loaded ZSM5 have been reported in the literature. These include aqueous ion exchange from ferrous oxalate, performed under exclusion of air [8], and solid-state ion exchange using $\mathrm{Fe}(\mathrm{II})$ chloride $[9,10], \mathrm{Fe}(\mathrm{III})$ chloride [11-14] or $\mathrm{FeSO}_{4} \cdot 7 \mathrm{H}_{2} \mathrm{O}$ [15]. The synthesis in aqueous solution with ferrous oxalate as precursor has led to results comparable to those obtained through the CVD of $\mathrm{FeCl}_{3}$, with respect to both the iron loading and the catalytic activity towards HC-SCR with isobutane. Nevertheless, the oxalate technique has shown lack of re- 
producibility, the reason being the difficulty in preventing the precipitation, during the synthesis, of neutral $\mathrm{FeC}_{2} \mathrm{O}_{4}$ complexes onto the pores mouth of the zeolite [16,17]. Via solid-state ion exchange the amount of iron loaded on the ZSM5 can easily be tuned during the synthesis. The solidstate ion exchanged Fe/ZSM5 has shown high activity in the catalytic decomposition of $\mathrm{N}_{2} \mathrm{O}$ [12] and in the HC-SCR of $\mathrm{NO}$ with isobutane [13]. However, the use of $\mathrm{FeCl}_{3}$ in its gaseous form has a clear advantage: by avoiding the contact between the ZSM5 support and the moisture always present in the precursor, it prevents the formation of large iron hydroxide and oxide clusters [11]. The result of the CVD is the highest possible dispersion of extra-framework iron at the acidic exchange positions of the lattice, coupled with a very high reproducibility of the synthesis.

The remarkable catalytic properties have made the overexchanged Fe/ZSM5 one of the most investigated materials in the last years. Several characterization studies have been performed in order to unravel the nature of the active phase $[1,2,11,12,18-23]$. Binuclear iron oxo-hydroxo clusters at the ion exchange positions of the ZSM5 lattice have been proposed earlier as the active phase for both the HC-SCR of NO $[1,2,18]$ and the catalytic decomposition of $\mathrm{N}_{2} \mathrm{O}$ [12]. This model is based on results obtained by characterization with $\mathrm{H}_{2}$ and $\mathrm{CO}$ TPR, XRD, FTIR, and EPR. X-ray absorption fine structure spectroscopy (XAFS) studies performed independently by our group [19] and by Marturano et al. [20,21] confirmed the presence of Fe binuclear oxo-hydroxo clusters in the over-exchanged Fe/ZSM5 obtained through CVD. Nevertheless, binuclear complexes are not the only Fe species present in over-exchanged Fe/ZSM5. In addition to binuclear Fe-oxocations, EPR has revealed the presence of oxo/hydroxo ions, such as $\left(\mathrm{Fe}(\mathrm{OH})_{2}\right)^{+}$or $(\mathrm{Fe}=\mathrm{O})^{+}$. Also the presence of a minor amount of iron oxide particles has been suggested [12,18,22].

While it is generally believed that the CVD of $\mathrm{FeCl}_{3}$ is able to produce the most homogeneous and reproducible over-exchanged Fe/ZSM5 material possible, the nature of the active sites is still under debate. Furthermore, the processes occurring to iron and to the ZSM5 support during the different steps of the synthesis are not satisfactorily described. A lack of information regards especially the influence of the calcination treatment.

In the present work a comprehensive characterization is presented, with the aim of tracking the evolution of iron and of the support after each step of the synthesis: sublimation of the $\mathrm{FeCl}_{3}$ into the zeolite pores; hydrolysis and washing of the residual chlorine; calcination. Different characterization techniques have been applied, including X-ray absorption spectroscopy (XAS), X-ray diffraction (XRD), $\mathrm{N}_{2}$ physisorption, electron energy loss spectroscopy (EELS), high-resolution transmission electron microscopy (HR-TEM), Fourier transform infra-red spectroscopy (FTIR), aluminum-nuclear magnetic resonance (Al-NMR) and Mössbauer spectroscopy. The goals of this study are:

(i) To understand the pathway by which the Fe binuclear complexes, i.e., the suggested catalytic active phase, are formed;

(ii) To study the structure of these complexes;

(iii) To identify and to control the processes responsible for their undesired further aggregation towards larger and presumably inactive clusters.

A modified calcination procedure is presented by which the agglomeration of iron can be significantly suppressed.

\section{Experimental}

\subsection{Preparation of the samples}

Over-exchanged $\mathrm{Fe} / \mathrm{ZSM} 5$ was prepared via the $\mathrm{FeCl}_{3}$ CVD method described by Chen and Sachtler [1]. $\mathrm{NH}_{4}$ / ZSM5 ( $\mathrm{Si} / \mathrm{Al}$ atomic ratio $=17$ ) obtained by Zeolyst, further referred to as $\mathrm{NH}_{4} / \mathrm{ZSM} 5-17$, was converted into the acidic form by calcination under $\mathrm{O}_{2}$ at $550{ }^{\circ} \mathrm{C}$ for $3 \mathrm{~h}$. For the CVD exchange a dedicated U-shaped quartz reactor was used. The reactor was built with a porous frit in each of the legs, allowing a separate loading of the H/ZSM5 support and the $\mathrm{FeCl}_{3}$ precursor. Furthermore, it could be isolated by closing two Pyrex valves mounted on its inlet and outlet. In order to remove absorbed moisture, $1.5 \mathrm{~g}$ of the H/ZSM5 (sieve fraction between 212 and $450 \mu \mathrm{m}$ ) were loaded onto one frit and flushed overnight under $\mathrm{He}$ $(40 \mathrm{ml} / \mathrm{min})$ at $300{ }^{\circ} \mathrm{C}$. The temperature was then lowered to $30^{\circ} \mathrm{C}$ under the same He flow. The reactor was sealed and moved to a glove bag (under $\mathrm{N}_{2}$ ), where $0.45 \mathrm{~g}$ of anhydrous $\mathrm{FeCl}_{3}$ (98\%, Acros Organics) were loaded on its second frit. After being reconnected to the He line $(30 \mathrm{ml} / \mathrm{min})$, the reactor was heated $\left(5{ }^{\circ} \mathrm{C} / \mathrm{min}\right)$ to $330{ }^{\circ} \mathrm{C}$ and kept at this temperature for $30 \mathrm{~min}$. The $\mathrm{HCl}$ formed during the reaction of the sublimated $\mathrm{FeCl}_{3}$ with the Brønsted sites of the support was absorbed in $100 \mathrm{ml}$ of $0.05 \mathrm{M} \mathrm{NaOH}$ solution for titration. After completion of the iron loading, the temperature was lowered to $30{ }^{\circ} \mathrm{C}$, the Pyrex valves were closed and the isolated reactor was moved to the $\mathrm{N}_{2}$ atmosphere of the glove bag. There, the synthesized $\mathrm{Fe} /$ ZSM5 was carefully extracted from the reactor, part of it being sealed and stored under $\mathrm{N}_{2}$ for characterization (sample further denoted as Fe/ZSM5-17-Cl). The remaining $\mathrm{Fe} / \mathrm{ZSM} 5$ was washed under stirring in $1000 \mathrm{ml}$ doubly deionized $\mathrm{H}_{2} \mathrm{O}$ for $30 \mathrm{~min}$ and dried overnight in air at $70{ }^{\circ} \mathrm{C}$. Part of the dried sample was isolated and stored under air $\left(\mathrm{Fe} / \mathrm{ZSM} 5-17-\mathrm{H}_{2} \mathrm{O}\right)$. The rest was pressed to obtain a sieve fraction between 150 and $212 \mu \mathrm{m}$, and divided into two batches which were subjected to two different calcination procedures. The first batch was heated under flowing oxygen in a tubular oven $\left(5^{\circ} \mathrm{C} / \mathrm{min}, 120 \mathrm{ml} / \mathrm{min}\right)$ and calcined at $550{ }^{\circ} \mathrm{C}$ for $3 \mathrm{~h}$. The sample deriving from this relatively 
severe calcination procedure will be denoted as Fe/ZSM517 -sc (severely calcined). For the calcination of the second batch a plug flow reactor (PFR) was used (ID $=1.2 \mathrm{~cm}$ ). Under a He flow of $800 \mathrm{ml} / \mathrm{min}$, the sample was heated with an extremely low temperature $\operatorname{ramp}\left(0.5^{\circ} \mathrm{C} / \mathrm{min}\right)$ to $200^{\circ} \mathrm{C}$. At this temperature, $200 \mathrm{ml} / \mathrm{min}$ of $\mathrm{O}_{2}$ were added to the $\mathrm{He}$ flow while, under the same temperature ramp, heating was continued to $550{ }^{\circ} \mathrm{C}$. After $3 \mathrm{~h}$ at $550{ }^{\circ} \mathrm{C}$ the temperature was decreased to $30^{\circ} \mathrm{C}$. The resulting sample, stored in air, will be referred to as Fe/ZSM5-17-mc (mildly calcined).

\subsection{Characterization}

\subsubsection{ICP, $\mathrm{HCl}$ titration, $\mathrm{N}_{2}$ physisorption}

The elemental composition of the starting H/ZSM5 support and of the obtained over-exchanged Fe/ZSM5 was determined by using inductively coupled plasma emission spectroscopy (ICP). The amount of $\mathrm{HCl}$ formed during the Fe loading was measured by acid-base titration. The derived $\mathrm{H}^{+}$removal efficiency was calculated as the molar ratio between the released $\mathrm{HCl}$ and the aluminum of the support, according to the exchange reaction

$\downarrow \mathrm{FeCl}_{3(\mathrm{~g})}+\mathrm{H}^{+} \rightarrow \mathrm{FeCl}_{2}{ }^{+}+\mathrm{HCl}_{(\mathrm{g})} \uparrow$.

The micropore volume of the ZSM5 crystals was determined by $\mathrm{N}_{2}$ physisorption, using a Micromeritics ASAP 2010. The measurements were performed at $77 \mathrm{~K}$, in the pressure range $0-1$ bars, after de-gassing the samples in vacuum at $200{ }^{\circ} \mathrm{C}$ for $16 \mathrm{~h} . \mathrm{N}_{2}$ physisorption data obtained on the Fe-loaded samples were corrected for the additional metal loading for comparison with the support.

\subsubsection{FTIR spectroscopy}

Interaction of the iron species with the Brønsted and the silanol sites of the support was investigated using Fourier transform infrared spectroscopy. Samples, pressed into selfsupporting wafers, were heated in situ under helium with a temperature ramp of $2{ }^{\circ} \mathrm{C} / \min$ to $350{ }^{\circ} \mathrm{C}$. Transmission infrared spectra were recorded under helium at $350{ }^{\circ} \mathrm{C}$ on a Perkin Elmer 2000 spectrometer using a DTGS detector. One hundred scans were recorded at a resolution of $4 \mathrm{~cm}^{-1}$ and averaged. Data were baseline-corrected and the intensity of each spectrum was normalized at the zeolite overtones $\left(1850-1950 \mathrm{~cm}^{-1}\right)$.

\subsection{3. $X R D$}

The crystalline fingerprint of the zeolitic support was compared after each synthesis step to visualize significant lattice damage or formation of large particles of iron oxidic or oxo-hydroxidic crystalline phases. X-ray diffraction (XRD) patterns were recorded by means of a Nonius PDS 120 powder diffractometer equipped with a curved position-sensitive INEL detector. The radiation used was Co- $\mathrm{K}_{\alpha 1}(\lambda=1.78897 \AA)$. In order to optimize the signalto-noise ratio XRD patterns were averaged after measuring for $24 \mathrm{~h}$.

\subsubsection{HR-TEM/EDX}

Imaging of the samples was obtained through highresolution transmission electron microscopy (HR-TEM). For this purpose a Philips CM30UT electron microscope was used with a field-emission gun operated at $300 \mathrm{kV}$ as the source of electrons. Measurements were performed also with a Philips CM200FEG operated at $200 \mathrm{kV}$. Samples were positioned on a carbon microgrid, supported on copper, by placing a few droplets of a suspension of ground sample in ethanol. The grid was dried at ambient conditions. When possible, identification of visible Fe-containing crystalline aggregates was performed on the basis of the observed lattice $d$-spacings. These were derived from high-resolution images and compared with literature XRD data. Elemental composition was obtained by energy dispersive analysis of X-rays (EDX) performed through a LINK EDX system.

\subsubsection{EELS/STEM}

Spatial distribution, migration and clustering of iron occurring during the synthesis were monitored by electron energy loss spectroscopy (EELS), at the $\mathrm{Fe}_{2,3}$-edges and the O K-edge. EELS was coupled with scanning transmission electron microscopy (STEM). The combination of these techniques provides very detailed morphological and spectroscopic information (including chemical composition) at the nanometer scale. The data were recorded with a scanning transmission electron microscope VGHB501, equipped with a field-emission source and a parallel Gatan 666 EELS spectrometer. This instrument produced EELS spectra with a typical $0.7 \mathrm{eV}$ resolution recorded from subnanometer areas $[24,25]$. In the line spectrum mode spectra were recorded while moving the probe with given steps across the specimen. Acquisition times required for achieving a satisfactory signal-to-noise level on core edges were in the order of $0.1-1.0 \mathrm{~s}$. The data recorded at the $\mathrm{Fe} \mathrm{L}_{2,3}$ and at the $\mathrm{O}$ K-edges were corrected by the corresponding elemental crossover sections. To obtain information on the concentration of iron in the ZSM5 crystals, the Fe intensity was divided by that of oxygen. By doing so, a homogeneous distribution of oxygen in the ZSM5 matrix was assumed at the scale of the investigation. Data obtained from local subareas were coupled to obtain information on larger areas. Data were analyzed by means of Savantic Spim Doctor 5.3 and Digital Micrograph 5.3 software.

\subsection{6. ${ }^{57} \mathrm{Fe}$ Mössbauer spectroscopy}

Agglomeration of iron was studied with Mössbauer spectroscopy. ${ }^{57} \mathrm{Fe}$ Mössbauer spectra were measured on a constant acceleration spectrometer in a triangular mode with a ${ }^{57} \mathrm{Co}: \mathrm{Rh}$ source. Mössbauer spectra were recorded at 300,77 , and $4.2 \mathrm{~K}$ in a closed cell with the sample in contact with He gas. The overall spectra were deconvoluted with calculated Mössbauer spectra consisting of Lorentzianshaped lines. In the case of quadrupole doublets the line widths and the adsorption areas of the constituent lines were constrained equally. Positional parameters were not 
constrained in the fitting process. Isomer shift values are reported relatively to sodium nitroprusside. The estimated accuracy of the positional parameters is $\pm 0.03 \mathrm{~mm} / \mathrm{s}$.

\subsection{7. ${ }^{27}$ Al MAS NMR, Al K-edge XAFS}

${ }^{27} \mathrm{Al}$ magic-angle spinning nuclear magnetic resonance $\left({ }^{27} \mathrm{Al}\right.$ MAS NMR) and Al K-edge X-ray absorption spectroscopy (Al K XAS) were combined to study the coordination of the $\mathrm{Al}$ atoms in the starting ZSM5 support and to track their evolution along the synthesis of Fe/ZSM5.

${ }^{27} \mathrm{Al}$ magic-angle spinning (MAS) NMR experiments were performed to determine the aluminum coordination in the ZSM5 support (ammonium and acidic form). The experiments were carried out on a Chemagnetics Infinity $600\left(14.1 \mathrm{~T}\right.$, corresponding to $156.3 \mathrm{MHz}{ }^{27} \mathrm{Al}$ resonance), using a $2.5 \mathrm{~mm}$ HX MAS probe head. Magic angle spinning (MAS) was performed at a rotation speed higher than $25 \mathrm{kHz}$. To allow a quantitative evaluation of the single pulse excitation, $\pi / 18$ pulses using a rf field strength of $\sim 35 \mathrm{kHz}$ were used. Chemical shifts were referenced relatively to a $1 \mathrm{M}$ aqueous $\mathrm{Al}\left(\mathrm{NO}_{3}\right)_{3}$ solution. The relaxation delays were $0.5 \mathrm{~s}$, determined to be adequate for a quantitative analysis using saturation recovery experiments. Samples were fully hydrated overnight in a controlled environment before measuring.

$\mathrm{X}$-ray absorption measurements of the $\mathrm{Al} \mathrm{K}$-edge ( $\mathrm{Al}$ K XAS) were performed on the starting ZSM5 support (ammonium and acidic form) and on the Fe/ZSM5 sample after severe calcination. The coordination of aluminum was deduced from the X-ray absorption near edge (XANES) by identification of characteristic features in the spectra [26]. Data were collected at station 3.4 of the SRS Daresbury (UK), using a double crystal monochromator equipped with YB66 crystals. A recently developed in situ low energy $\mathrm{X}$-ray absorption fine structure spectroscopy set-up (ILEXAFS) was used $[27,28]$. The samples were pressed into selfsupporting wafers and measured at room temperature under high vacuum $\left(P<10^{-5}\right.$ bar). Fluorescence detection, via a gas proportional counter (GPC), was used. Normalization of the data was performed through standard procedures [38].

\subsection{Fe K-edge HR-XANES}

\subsubsection{Experimental setup}

High-resolution X-ray absorption near edge spectroscopy (HR-XANES) was used to study the oxidation state and the local coordination geometry of Fe. The HR-XANES measurements at the $\mathrm{Fe} \mathrm{K}$-edge were carried out at the inelastic $\mathrm{X}$-ray scattering undulator beamline ID16 at the European Synchrotron Radiation Facility (ESRF). The set-up of the beamline has been described in detail elsewhere [29]. The white beam is monochromatized by a $\mathrm{Si}$ (111) double crystal device. The fluorescence signal is detected by a $1 \mathrm{~m}$ Rowland circle spectrometer consisting of a spherically bent $\mathrm{Si}$ (531) single-crystal wafer. The analyzer is operated at the $\mathrm{Fe}-\mathrm{K}_{\beta}$ emission line, with a typical resolution of $0.4 \mathrm{eV}$. Using this high-resolution fluorescence detector yields a spectral sharpening of the XANES spectrum below its lifetime broadening of $2 \mathrm{eV}[30,31]$. Hematite was used as internal reference for the energy calibration of the monochromator.

\subsubsection{HR-XANES data collection and processing}

Samples were pressed to obtain self-supporting wafers and placed in an in situ fluorescence cell [32] at $45^{\circ}$ with respect to the beam. After flushing with $\mathrm{He}$ at $30^{\circ} \mathrm{C}$ and atmospheric pressure, the cell was closed and the spectra were collected.

The fluorescence Fe K XANES spectra were normalized using the average absorption coefficient in the 7200$7300 \mathrm{eV}$ region. In order to isolate the pre-edge feature, the contribution of the edge jump to the pre-edge was calculated using a cubic spline function obtained by interpolating the data several eVs before and after the pre-edge.

The influence of fluorescence saturation effects was checked using the procedure as outlined in Ref. [33]. These effects were revealed in particular on $\alpha-\mathrm{Fe}_{2} \mathrm{O}_{3}$. Nevertheless, numerical comparison showed that as far as the pre-edge is concerned, it was possible to correct for the them by dividing the maximum intensity of the background subtracted fluorescence pre-edge by that of the corresponding transmission spectrum. For this purpose XANES spectra measured in transmission on each sample at beamline X1.1 at Hasylab (vide infra) were used as internal standard.

The normalized height, centroid position, half-width, and integrated intensity of the obtained pre-edge features were obtained using the software Grams. Prior to calculations, the pre-edge of $\alpha-\mathrm{Fe}_{2} \mathrm{O}_{3}$ was deconvoluted into pseudo-Voigt components (50\% Gaussian, 50\% Lorentzian peaks shape). Contribution to the centroid position and to the integrated intensity from components centered above $7115.0 \mathrm{eV}$ was ignored $[34,35]$. The estimated accuracy in the energy determination for the HR-XANES spectra presented in this study is $\pm 0.05 \mathrm{eV}$.

\subsection{Fe K-edge XAFS}

\subsubsection{XAFS data collection}

Fe K-edge XAFS was applied in combination with Fe K-edge HR-XANES in order to study the atomic environment around iron. X-ray absorption spectra of the Fe Kedge were collected at Hasylab (Hamburg, Germany) Wiggler Station X1.1, using a Si (111) double crystal monochromator. The monochromator was detuned to $50 \%$ of the maximum intensity to avoid higher harmonics in the X-ray beam. The measurements were performed in transmission mode using ion chambers filled with Ar to have a X-ray absorbance of $20 \%$ in the first ion chamber and of $80 \%$ of the remaining radiation in the second one. In all the experiments a Fe foil was measured using a third ionization chamber. The edge position was determined for each scan by calibrating the monochromator with the iron foil. The samples 
Table 1a

Crystallographic data and forward/inverse Fourier transform ranges used to produce the EXAFS Fe-O reference file

\begin{tabular}{|c|c|c|c|c|c|c|c|}
\hline \multirow[t]{2}{*}{ Atom pair } & \multirow[t]{2}{*}{ Ref compd } & \multirow[t]{2}{*}{ Ref. } & \multirow[t]{2}{*}{$N$} & \multirow[t]{2}{*}{$R(\AA)$} & \multirow[t]{2}{*}{$k$ weighting } & Forward FT & $\overline{\text { Inverse FT }}$ \\
\hline & & & & & & $\Delta k\left(\AA^{-1}\right)$ & $\Delta R(\AA)$ \\
\hline $\mathrm{Fe}-\mathrm{O}$ & Ferric(acac) & [40] & 6 & 1.99 & $k^{3}$ & $2.5-13.3$ & $0.7-2.2$ \\
\hline
\end{tabular}

were pressed into self-supporting wafers and placed in a controlled atmosphere cell [32]. Spectra were recorded at liquid nitrogen temperature after flushing the cell with $\mathrm{He}$ at $30^{\circ} \mathrm{C}$.

\subsubsection{XAFS data processing}

Extraction of the EXAFS data from the measured absorption spectra was performed with the XDAP code developed by Vaarkamp et al. [36]. Three scans were averaged and the pre-edge was subtracted using a modified Victoreen curve [37]. The background was subtracted employing cubic spline routines with a continuously adjustable smooth parameter [38,39]. Normalization was performed by dividing the data by the intensity of the absorption spectrum at $50 \mathrm{eV}$ above the $\mathrm{Fe} \mathrm{K}$ edge.

\subsubsection{EXAFS phase shifts and backscattering amplitudes}

Data for $\mathrm{Fe}-\mathrm{O}$ were obtained directly from experimental EXAFS data of ferric acetylacetonate. Table 1a gives the crystallographic data [40] and the forward and inverse Fourier transform ranges used to create the $\mathrm{Fe}-\mathrm{O}$ reference. The $\mathrm{Fe}-\mathrm{Fe}$ and $\mathrm{Fe}-\mathrm{Cl}$ phase shifts and backscattering amplitudes were calculated using the software FEFF7 [41]. The $\mathrm{Fe}-\mathrm{Fe}$ and the $\mathrm{Fe}-\mathrm{Cl}$ references were calibrated on the EXAFS data obtained from $\mathrm{Fe}_{2} \mathrm{O}_{3}$ (hematite) and $\mathrm{FeCl}_{3}$. $\left(6 \mathrm{H}_{2} \mathrm{O}\right)$, respectively, by fitting in $R$-space (see Tables $1 \mathrm{~b}$ and $1 \mathrm{c}$ ). The following average crystallographic parameters were used for the $R$-space fit of hematite: $\mathrm{Fe}-\mathrm{O}_{1}$ $(N=3, R=1.95 \AA) ; \mathrm{Fe}-\mathrm{O}_{2}(N=3, R=2.12 \AA) ; \mathrm{Fe}-\mathrm{Fe}_{1}$ $(N=4, R=2.95 \AA) ; \mathrm{Fe}-\mathrm{Fe}_{2}(N=3, R=3.36 \AA)$; $\mathrm{Fe}^{-\mathrm{Fe}_{3}}(N=7, R=3.74 \AA$ ) [42]. The crystallographic parameters adopted for the fit of the closest shells in $\mathrm{FeCl}_{3}$. $\left(6 \mathrm{H}_{2} \mathrm{O}\right)$ were: $\mathrm{Fe}-\mathrm{Cl}(N=2, R=2.31 \AA) ; \mathrm{Fe}-\mathrm{O}(N=4$, $R=2.07 \AA$ ) [43]. Both the reference spectra and the samples were measured at liquid nitrogen temperature. This means that temperature effects (dynamic disorder) can be ruled out in the difference of the Debye-Waller factor $\left(\Delta \sigma^{2}\right)$ between the samples and the reference.

\subsubsection{EXAFS data analysis}

The EXAFS data analysis was performed by applying multiple-shell fitting in $R$-space. $R$-space fitting has important advantages compared to the usually applied fitting in $k$-space and is extensively discussed in a recent paper by Koningsberger et al. [38]. The difference file technique was applied together with phase-corrected Fourier transforms to resolve the different contributions in the EXAFS data [38]. The EXAFS fits were checked by applying $k^{1}, k^{2}$, and $k^{3}$ weightings.

The number of independent data points $\left(N_{\text {indp }}\right)$ was determined as outlined in the "Reports on Standard and Criteria in XAFS Spectroscopy" [44]

$N_{\text {indp }}=\frac{2 \Delta k \Delta R}{\pi}+2$.

Errors in the numerical values obtained by the EXAFS data analysis are estimated to be $\pm 10 \%$ in the coordination number $(N), \pm 1 \%$ in the distance $(R), \pm 5 \%$ in the DebyeWaller factor $\left(\Delta \sigma^{2}\right)$, and $\pm 10 \%$ in the inner potential correction $\left(\Delta E_{0}\right)$ [45]. In this study the statistical significance of each contribution has been checked by comparing the amplitude of (Fit) $j$ with the noise level present in the experimental data.

\section{Results}

\subsection{ICP, $H^{+}$removal efficiency, $N_{2}$ physisorption}

The elemental composition of the parent H/ZSM5 support and of the Fe/ZSM5 samples is presented in Table 2. In the same table the $\mathrm{H}^{+}$removal efficiency (calculated from the titrated $\mathrm{HCl}$ ) is compiled, together with the evolution of the micropore volume of the support. The $\mathrm{Si} / \mathrm{Al}$ ratio of the parent H/ZSM5 was maintained after the ion exchange and the subsequent washing procedure, indicating that no significant amount of aluminum was leached out during the synthesis. The $\mathrm{FeCl}_{3} \mathrm{CVD}$ procedure led to an iron content of $\mathrm{Fe} / \mathrm{Al}=1.0$ as a result of the complete exchange with the Brønsted protons. Completion of the $\mathrm{H}^{+}$removal was confirmed by titration of the $\mathrm{HCl}$ released during the synthesis. After the loading of iron a decrease of around $20 \%$ in the micropore volume was detected by $\mathrm{N}_{2}$ physisorption ( $\left.\mathrm{Fe} / \mathrm{ZSM} 5-17-\mathrm{H}_{2} \mathrm{O}\right)$. While applying a mild calcination procedure resulted in no significant change of the micropore volume (Fe/ZSM5-17-mc), the latter was partially regained

Table $1 \mathrm{~b}$

Crystallographic data and input parameters for FEFF 7 used to produce the EXAFS Fe-Fe and $\mathrm{Fe}-\mathrm{Cl}$ reference files

\begin{tabular}{|c|c|c|c|c|c|c|c|c|}
\hline Atom pair & Ref compd & Ref. & $N$ & $R(\AA)$ & $\Delta \sigma^{2}$ & $V_{\mathrm{r}}(\mathrm{eV})$ & $V_{\mathrm{i}}(\mathrm{eV})$ & $S_{0}^{2}$ \\
\hline $\mathrm{Fe}-\mathrm{Fe}$ & $\alpha-\mathrm{Fe}_{2} \mathrm{O}_{3}$ & {$[42]$} & 4 & 2.95 & 0.013 & -16.0 & 3 & 0.53 \\
\hline $\mathrm{Fe}-\mathrm{Cl}$ & $\mathrm{FeCl}_{3} \cdot 6 \mathrm{H}_{2} \mathrm{O}$ & [43] & 2 & 2.31 & 0.002 & 1.0 & 3 & 0.91 \\
\hline
\end{tabular}


Table 1c

Structural parameters (closest Fe-Fe shell in hematite and closest $\mathrm{Fe}-\mathrm{Cl}$ shell in ferric chloride hexahydrate), as obtained from the $R$-space fit by using the theoretical references

\begin{tabular}{|c|c|c|c|c|c|c|c|c|}
\hline \multirow[t]{2}{*}{ Atom pair } & \multicolumn{2}{|c|}{$k^{1}$ Fourier transform } & \multicolumn{4}{|c|}{ Structural parameters } & \multicolumn{2}{|c|}{ Variance } \\
\hline & $\Delta k\left(\AA^{-1}\right)$ & $\Delta R(\AA)$ & $N$ & $R(\AA)$ & $\Delta \sigma^{2}\left(\AA^{2}\right)$ & $\Delta E_{0}(\mathrm{eV})$ & $\mathrm{Im}$. & Abs. \\
\hline $\mathrm{Fe}-\mathrm{Fe}$ & $3.0-13.0$ & $1.0-3.5$ & 4.0 & 2.95 & 0 & 0 & 0.62 & 0.38 \\
\hline $\mathrm{Fe}-\mathrm{Cl}$ & $3.0-13.0$ & $1.0-2.2$ & 2.0 & 2.31 & 0 & 0 & 0.13 & 0.07 \\
\hline
\end{tabular}

(reincrease between 5 and 10\%) after a severe calcination (Fe/ZSM5-17-sc).

\subsection{FTIR spectroscopy}

The normalized spectra of the hydroxyl stretching region $\left(3900-3000 \mathrm{~cm}^{-1}\right)$ are depicted in Fig. 1. For H/ZSM5-17 two intense bands were observed at 3590 and $3740 \mathrm{~cm}^{-1}$. They are assigned respectively to Brønsted acid groups (associated with framework aluminum $(\mathrm{Si}(\mathrm{OH}) \mathrm{Al}))$ and to terminal silanol groups (located inside the zeolite channels and on the external surface) [46-48], respectively. A small shoulder detected at $3650 \mathrm{~cm}^{-1}$ is attributed to hydroxyl groups of extra-framework aluminum species [49]. Following $\mathrm{FeCl}_{3}$ CVD and washing ( $\mathrm{Fe} / \mathrm{ZSM} 5-17-\mathrm{H}_{2} \mathrm{O}$, Fig. 1), the intensity of the band at $3590 \mathrm{~cm}^{-1}$ decreased significantly, as a result of the exchange of the Brønsted protons by iron, while the signal from the silanol groups remained unchanged. In addition, a new band appeared at $3715 \mathrm{~cm}^{-1}$. This band is ascribable to the stretching vibration of hydrolyzed $\mathrm{Fe}$ species formed upon washing of the residual chlorine [20], and disappeared after calcination (Fe/ZSM5-17-mc, Fe/ZSM517 -sc). No clear changes were detected upon calcination in the intensity of the silanol and of the Al-Brønsted signal. It should nevertheless be noted that, due to differences in the broadening of the $\mathrm{Al}-\mathrm{OH} \mathrm{Br} ø$ nsted and $\mathrm{Si}-\mathrm{OH}$ silanol bands, a quantitative comparison between washed and calcined sample is not possible.

\section{3. $X R D$}

X-ray diffractograms (not shown) were collected after each synthesis step and compared to that of the parent $\mathrm{H} /$ ZSM5. All patterns appeared to be identical, indicating no detectable damage to the ZSM5 structure. In addition, no contribution in the XRD patterns was detected from reflec-

Table 2

Elemental composition (ICP), $\mathrm{H}^{+}$removal efficiency and micropore volume $\left(\mathrm{N}_{2}\right.$ physisorption)

\begin{tabular}{lcccc}
\hline Samples & $\begin{array}{c}\mathrm{Si} / \mathrm{Al} \\
\text { (atomic } \\
\text { ratio) }\end{array}$ & $\begin{array}{c}\mathrm{Fe} / \mathrm{Al} \\
\text { atomic } \\
\text { ratio })\end{array}$ & $\begin{array}{c}\mathrm{H}^{+} \text {removal } \\
\text { efficiency }\end{array}$ & $\begin{array}{c}\text { Micropore } \\
\text { volume } \\
\left(\mathrm{cm}^{3} / \mathrm{g}\right)\end{array}$ \\
\hline $\mathrm{H}$ /ZSM5-17 & 17.0 & 0.0 & - & 0.15 \\
Fe/ZSM5-17-H $2 \mathrm{O}$ & 17.4 & 1.0 & 1.0 & 0.12 \\
Fe/ZSM5-17-mc & 17.2 & 1.0 & - & 0.12 \\
Fe/ZSM5-17-sc & 17.2 & 1.0 & - & 0.13 \\
\hline
\end{tabular}

tions ascribable to Fe oxidic or oxo-hydroxidic crystalline phases.

\section{4. $H R-T E M / E D X$}

High-resolution transmission electron micrographs of the over-exchanged Fe/ZSM5, collected in Fig. 2, were taken upon sublimation and washing $\left(\mathrm{Fe} / \mathrm{ZSM} 5-17-\mathrm{H}_{2} \mathrm{O}\right)$, and after the different calcination procedures. As expected, no particles were visible on the $\mathrm{Fe} / \mathrm{ZSM} 5-17-\mathrm{H}_{2} \mathrm{O}$ (Fig. 2a), suggesting that no agglomeration of iron occurred during the Fe-exchange process and the following washing. At this stage of the synthesis $\mathrm{Fe}$ is highly dispersed within the zeolite channels. The uniform distribution of iron was confirmed by elemental analysis performed on local areas $(D \sim 100 \mathrm{~nm})$ by EDX. In a few EDX measurements traces of residual chlorine were found.

TEM images collected from the sample upon mild calcination (not shown here) did not reveal significant changes when compared to those obtained after washing. Nevertheless, when HR-TEM was applied in combination with EDX, some coalescing iron was revealed on the external surface of the Fe/ZSM5-mc crystals. This was visible as infrequent dark spots with sizes between 2 and $5 \mathrm{~nm}$. In addition, very few crystalline particles were detected. In Fig. $2 b$ one of these Fe-containing crystals is depicted. From the largest Fe-containing particles detected on Fe/ZSM5-17-mc the following $d$-spacing could be determined: $2.85,2.66$, and $2.53 \AA$ (estimated margin of error equal to $\pm 0.05 \AA$ ).

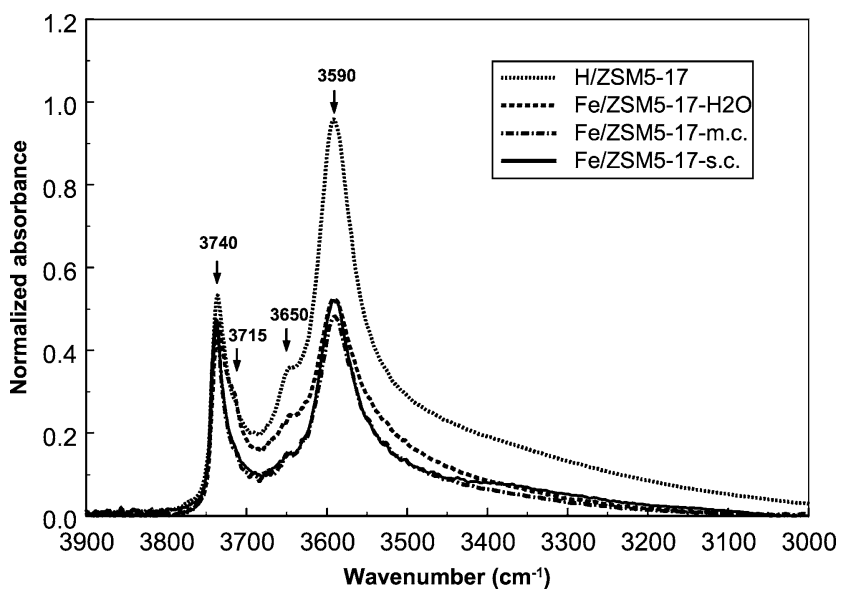

Fig. 1. Infrared spectra of the hydroxyl stretching region for H/ZSM5-17 and $\mathrm{Fe} /$ ZSM5-17, measured at $350{ }^{\circ} \mathrm{C}$ in helium (heating ramp of $\left.2{ }^{\circ} \mathrm{C} / \mathrm{min}\right)$. 


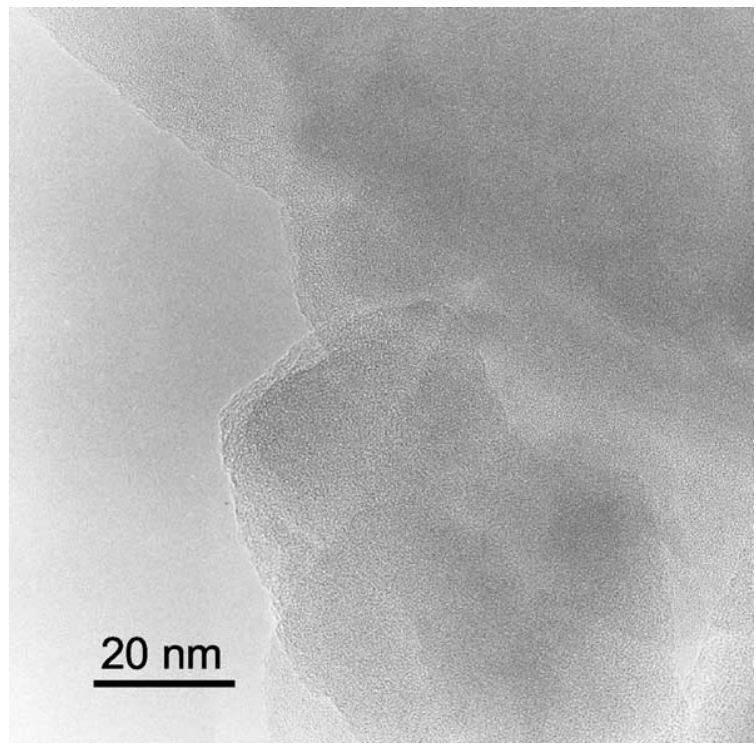

(a)

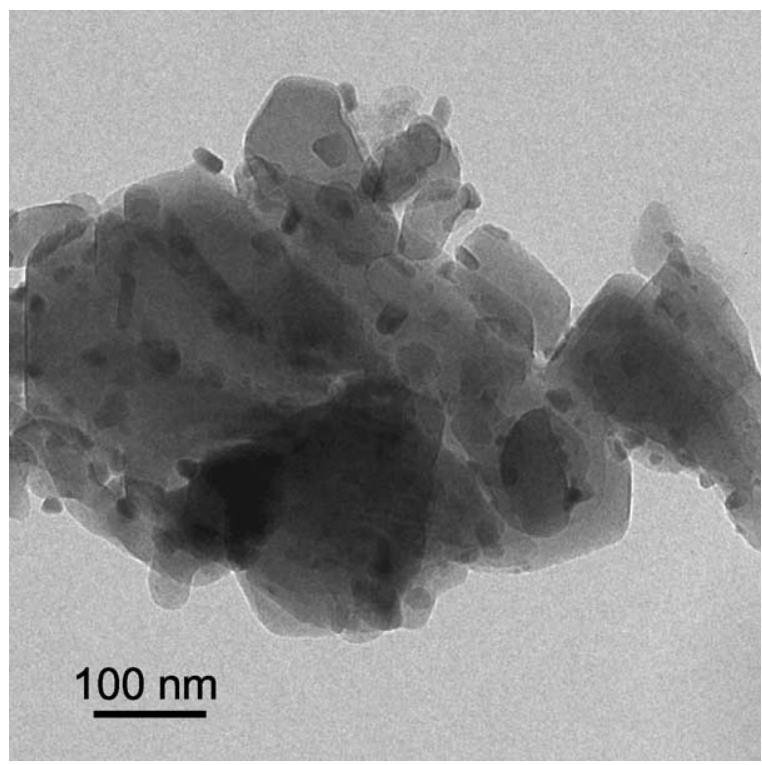

(c)

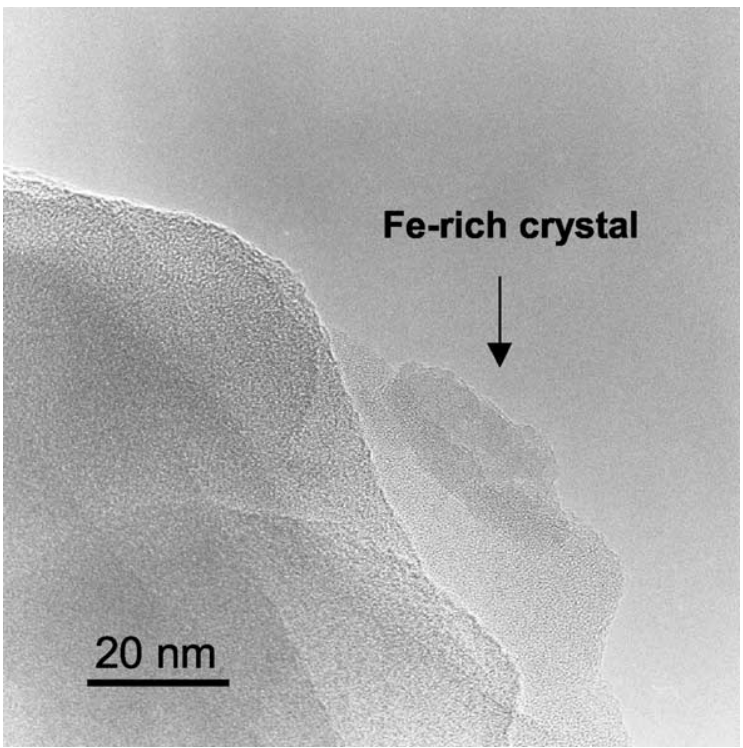

(b)

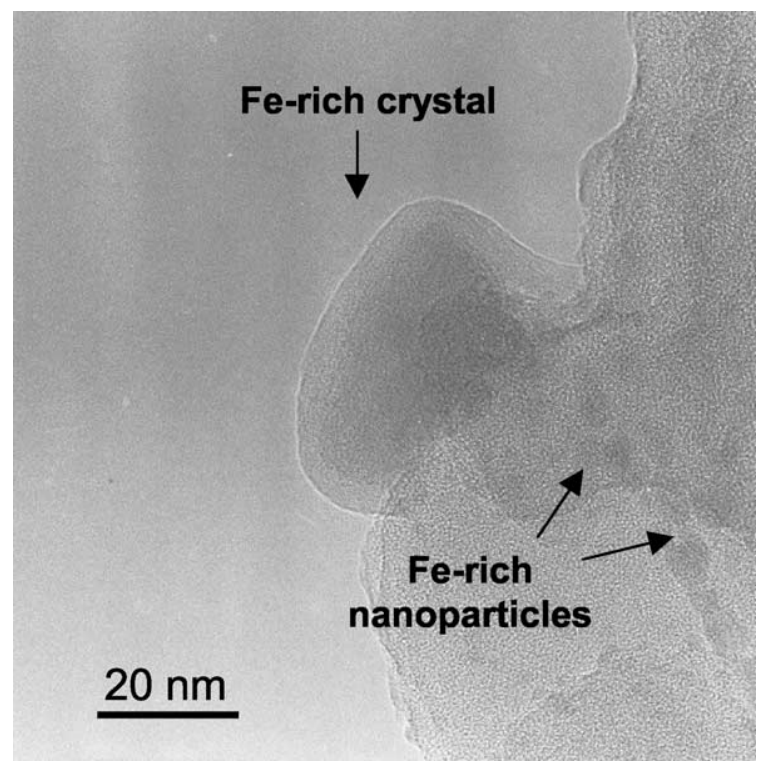

(d)

Fig. 2. TEM micrographs of Fe/ZSM5- $\mathrm{H}_{2} \mathrm{O}$ (a), Fe/ZSM5-17-mc (b), Fe/ZSM5-17-sc (c, d).

By comparison with XRD data obtained from the literature [50], these Fe-containing particles are identified as oxohydroxides like $\alpha$-goethite $(2.53$ and $2.69 \AA)$ or $\beta$-goethite ( 2.55 and $2.63 \AA)$, and possibly hematite (2.52 and $2.70 \AA)$.

Severe calcination, on the other hand, leads to considerable aggregation of iron in the Fe/ZSM5 material. This can clearly be seen when observing the micrographs obtained from the severely calcined Fe/ZSM5 (Figs. 2c and 2d). Already at medium magnification (Fig. 2c) clustering into iron-rich particles is clearly visible. When compared to the $\mathrm{Fe} / \mathrm{ZSM} 5-17-\mathrm{mc}$, the number of particles is drastically increased, together with their average dimension and degree of crystallization. A HR-TEM picture (Fig. 2d) shows one large crystalline Fe-containing particle of around $40 \mathrm{~nm}$, together with some Fe-rich clusters of 1-2 nm. $D$-spacings obtained from this sample are 3.33, 3.26, and $2.53 \AA$. While the $d$-spacing at $2.53 \AA$ can be attributed to either $\alpha$-goethite or hematite, those at $\sim 3.3 \AA$ are typical only of goethite-like oxo-hydroxo crystalline structures [50].

\subsection{EELS/STEM}

In Fig. 3a the oxygen map of a Fe/ZSM5-17- $\mathrm{H}_{2} \mathrm{O}$ crystal is shown. The picture, produced from EELS O K-edge absorption spectra recorded with spatial step increments of $2.5 \mathrm{~nm}$ and a probe diameter of $0.5 \mathrm{~nm}$, is plotted in grayscale (oxygen in white). In this image luminosity is proportional to the number of oxygen atoms encountered in each sub-area by the electron beam. In Fig. 3b the $\mathrm{Fe} / \mathrm{O}$ map (atomic ratio) of the same region is depicted. In 


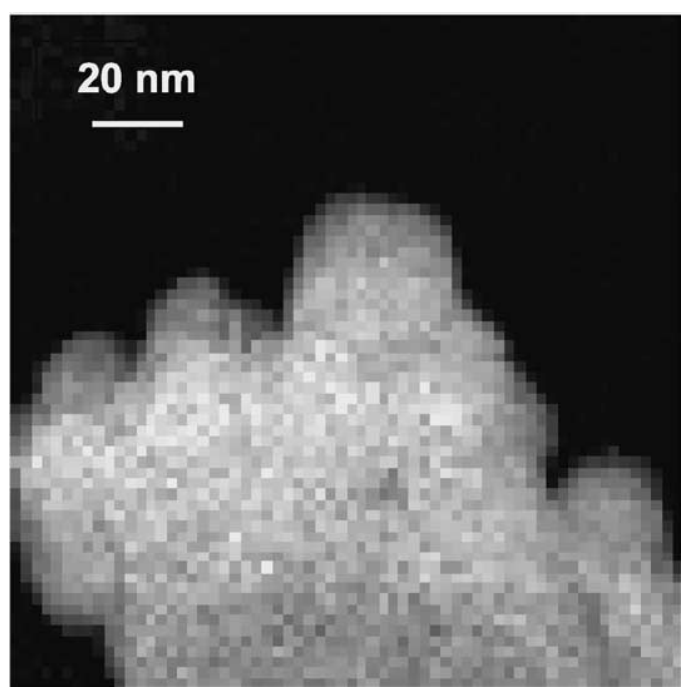

(a)

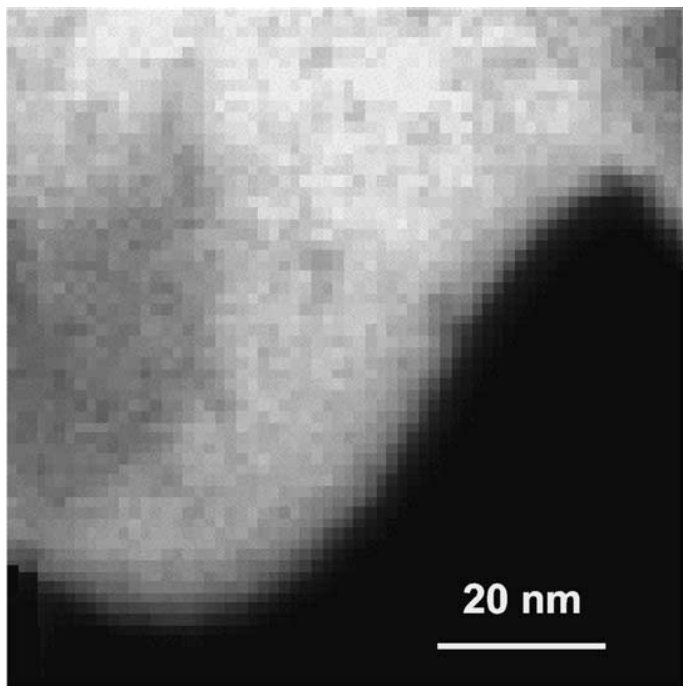

(c)

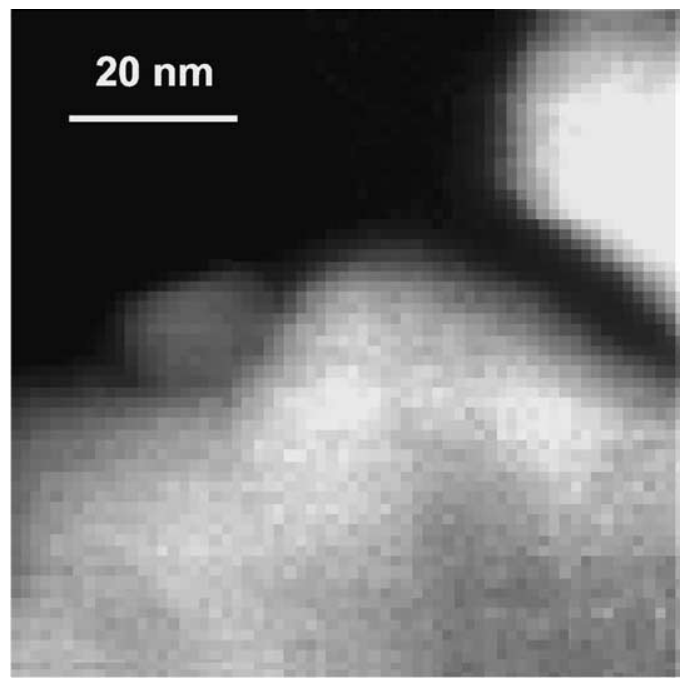

(e)

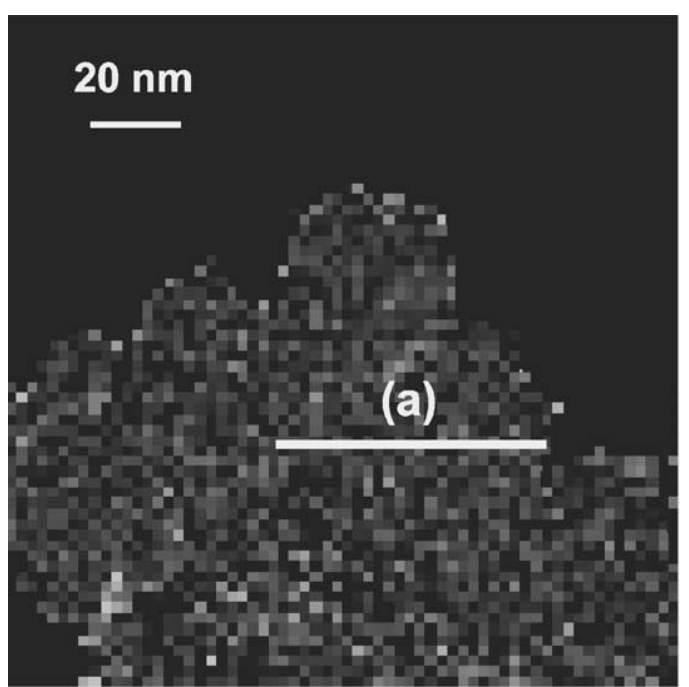

(b)

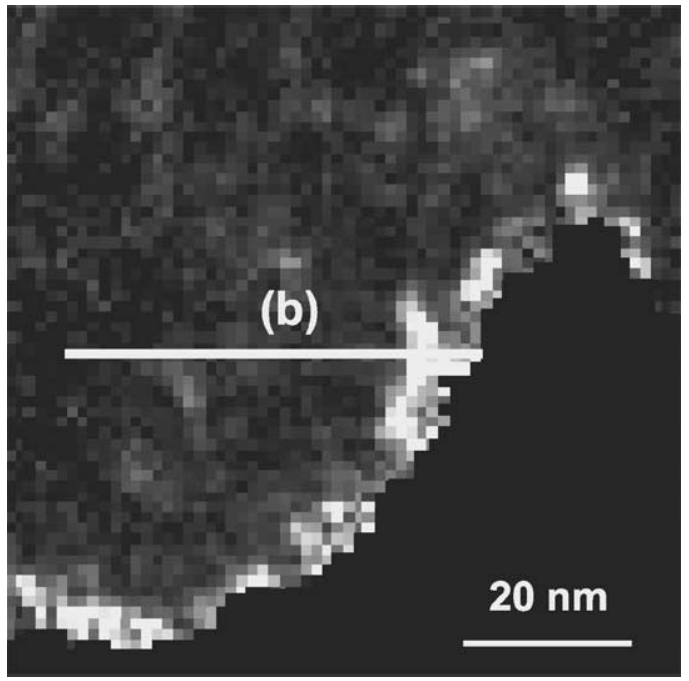

(d)

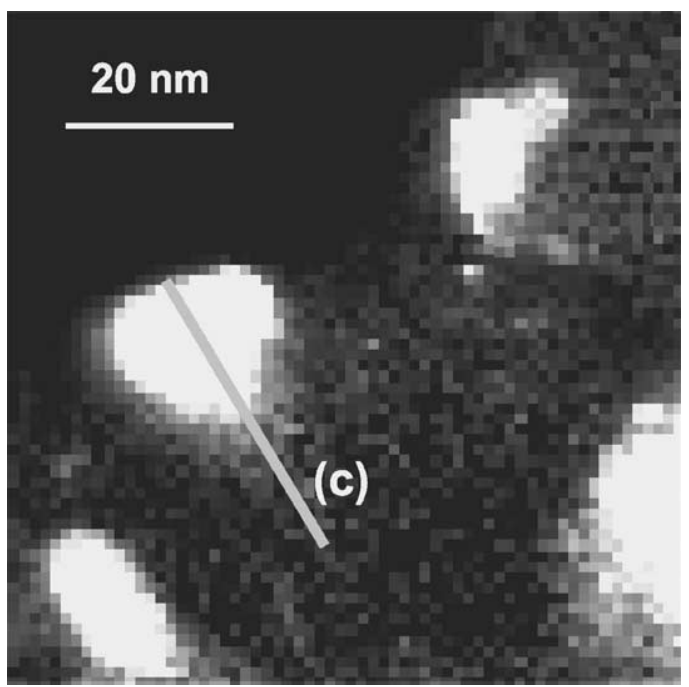

(f)

Fig. 3. Grayscales EELS: (a) (O K-edge) oxygen map of Fe/ZSM5-17- $\mathrm{H}_{2} \mathrm{O}$ (oxygen depicted in white); (b) Fe/O map (atomic ratio) of Fe/ZSM5-17-H 2 O (iron depicted in white); (c) (O K-edge) oxygen map of Fe/ZSM5-17-mc; (d) Fe/O map (atomic ratio) of Fe/ZSM5-17-mc; (e) (O K-edge) oxygen map of Fe/ZSM5-17-sc; (f) Fe/O map (atomic ratio) of Fe/ZSM5-17-sc. 
the $\mathrm{Fe} / \mathrm{O}$ map brightness is proportional to the concentration of iron. Due to the uniform distribution of oxygen in the ZSM5 support, the $\mathrm{Fe} / \mathrm{O}$ ratio provides information on the local concentration of iron in the crystal. From Fig. $3 \mathrm{~b}$ it can be concluded that, after $\mathrm{FeCl}_{3} \mathrm{CVD}$ and washing, iron was homogeneously distributed across the crystal. In particular, no gradient in the iron concentration was detected when approaching the crystal surface. Furthermore, the calculated $\mathrm{Fe} / \mathrm{O}$ ratio, obtained by integration over the whole sampling area, was 0.028 , in good agreement with the $\mathrm{Fe}$ content detected by bulk ICP elemental analysis.

The $\mathrm{O}$ and $\mathrm{Fe} / \mathrm{O}$ map of the edge of a $\mathrm{Fe} / \mathrm{ZSM} 5$ crystal after mild calcination are collected in Figs. 3c and $3 \mathrm{~d}$, respectively. The pictures were produced from spectra recorded with a spatial step increment of $1.25 \mathrm{~nm}$ (the probe diameter was kept at $0.5 \mathrm{~nm}$ ). In this case the Fe concentration appeared to be higher in the proximity of the external surface. Furthermore, the $\mathrm{Fe} / \mathrm{O}$ ratio integrated over the whole area was 0.054 , thus showing a clear increase in the Fe content when compared to that of the sample after washing. This is ascribed to the migration towards the edge of the crystal of iron, which prior to the mild calcination procedure, was still located well inside the crystal. This migration was nevertheless not accompanied by the formation of clearly visible particles on the surface.

The formation of well defined Fe-rich particles, on the contrary, was clearly visible on the external surface of the severely calcined sample, as shown in Figs. 3e and 3f. Four Fe-containing clusters with an average dimension of $20 \mathrm{~nm}$ are visible (Fig. 3f). One of them is recognizable also in the upper-left part of the corresponding $\mathrm{O}$ map (Fig. 3e). This indicates that the cluster was located on the external surface of the ZSM5. As a consequence, its chemical composition could be obtained, avoiding misleading information from the ZSM5 support. The result is shown in Fig. 4. In this figure three $\mathrm{Fe} / \mathrm{O}$ line scans are plotted, measured along the lines $\mathrm{a}, \mathrm{b}$, and $\mathrm{c}$, selected respectively from the $\mathrm{Fe} / \mathrm{O}$

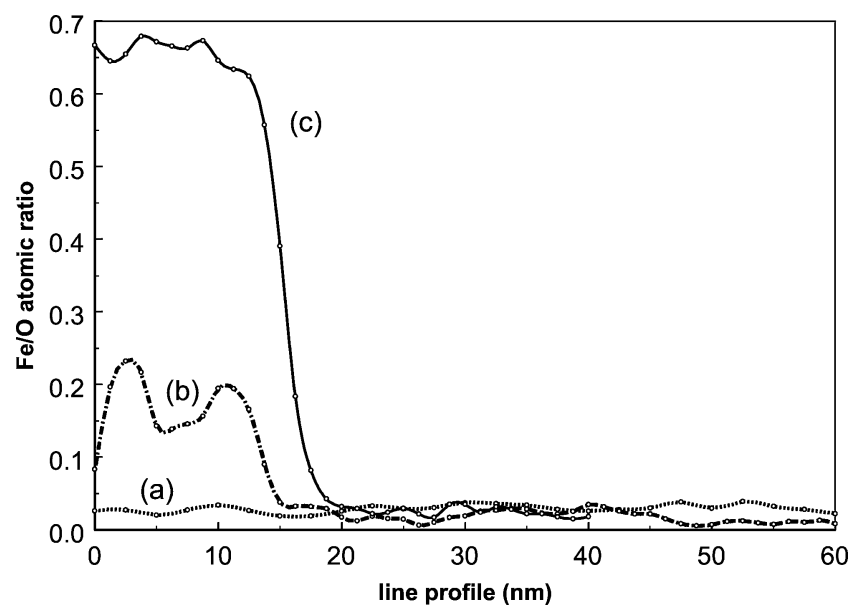

Fig. 4. Fe/O scans (atomic ratio) measured along lines: (a) Fe/ZSM517- $\mathrm{H}_{2} \mathrm{O}$, from Fig. 3b; (b) Fe/ZSM5-17-mc, from Fig. 3d; (c) Fe/ZSM517 -sc, from Fig. $3 \mathrm{f}$. maps of Figs. 3b, 3d, and 3f. These line scans show the concentration of iron in the different samples as a function of the distance from the crystal surface. Line a (Fe/ZSM5-17$\mathrm{H}_{2} \mathrm{O}$ ) shows a homogeneous $\mathrm{Fe} / \mathrm{O}$ profile over the whole distance, confirming the homogeneous dispersion of iron within the zeolite channels after CVD and washing. After applying a mild calcination (line b), a clear increase in the Fe signal was visible when approaching the crystal surface $(0-15 \mathrm{~nm})$. Quantification of the $\mathrm{Fe} / \mathrm{O}$ ratio in the Fe-rich phase alone was not possible due to its overlap with the ZSM5. It should be noted that the Fe concentration of line $b$ in the region 20-60 $\mathrm{nm}$ is somewhat lower than that of line a. This shows that the agglomeration at the crystal surface was produced by migration of iron from inside the crystal. Prior to calcination this iron was still homogeneously distributed in the zeolite channels. Line c shows the influence on the Fe agglomeration of a severe calcination procedure. The datapoints in the $0-15 \mathrm{~nm}$ region of line $\mathrm{c}$ are of the EELS scan across the Fe-containing cluster mentioned above. The $\mathrm{Fe} / \mathrm{O}$ ratio in this region is 0.67 . By coupling this result with that of HR-TEM, this particle is identified as $\alpha-\mathrm{Fe}_{2} \mathrm{O}_{3}$. Also for line $\mathrm{c}$ a decrease in the Fe concentration was visible when scanning the internal region of the ZSM5 crystal (20$40 \mathrm{~nm}$ ). In this case the decrease appears less pronounced than for the mildly calcined sample. This is probably due to the presence of some additional $\mathrm{Fe}$ aggregation in the vicinity of the hematite crystal.

\section{6. ${ }^{57} \mathrm{Fe}$ Mössbauer spectroscopy}

${ }^{57} \mathrm{Fe}$ Mössbauer spectra were recorded under $\mathrm{He}$ at 300, 77, and $4.2 \mathrm{~K}$. In Fig. 5a the spectra of the Fe/ZSM5$17-\mathrm{H}_{2} \mathrm{O}$ are shown. At $300 \mathrm{~K}$ (spectrum a) a doublet was detected with an isomer shift (IS) of $0.61 \mathrm{~mm} / \mathrm{s}$ and a quadrupole splitting (QS) equal to $1.02 \mathrm{~mm} / \mathrm{s}$. The presence of this well resolved paramagnetic doublet is the result of high electron spin relaxation rates due to the mutual magnetic interaction of $\mathrm{Fe}^{3+}$ neighboring atoms. This shows that, after CVD and washing, Fe was not present as monoatomic species at the Al-exchange position of the lattice. By lowering the temperature to $77 \mathrm{~K}$ (spectrum $\mathrm{b}$ ) an additional doublet was detected with a QS of $3.37 \mathrm{~mm} / \mathrm{s}$, assigned to $\mathrm{Fe}^{2+}$. The $\mathrm{Fe}^{2+}$ doublet accounts for around $8 \%$ of the overall signal. At $4.2 \mathrm{~K}$ (spectrum c), together with the doublets, also the contribution of a weak sextet became visible, with an average hyperfine field (HF) of $46.7 \mathrm{~T}$. The presence of the sextet is ascribed to the magnetic ordering of a fraction of iron [51]. This indicates the presence of some Fe agglomeration occurring already after washing. The extreme width of the sextet is an indication for the amorphous character of the aggregated phase. The hyperfine parameters of the $\mathrm{Fe} / \mathrm{ZSM} 5-17-\mathrm{H}_{2} \mathrm{O}$, together with the relative integrated intensity of the different $\mathrm{Fe}$ species are collected in Table $3 \mathrm{a}$.

Figure $5 b$ shows the spectra of the Fe/ZSM5 sample after the mild calcination procedure. No significant differences 


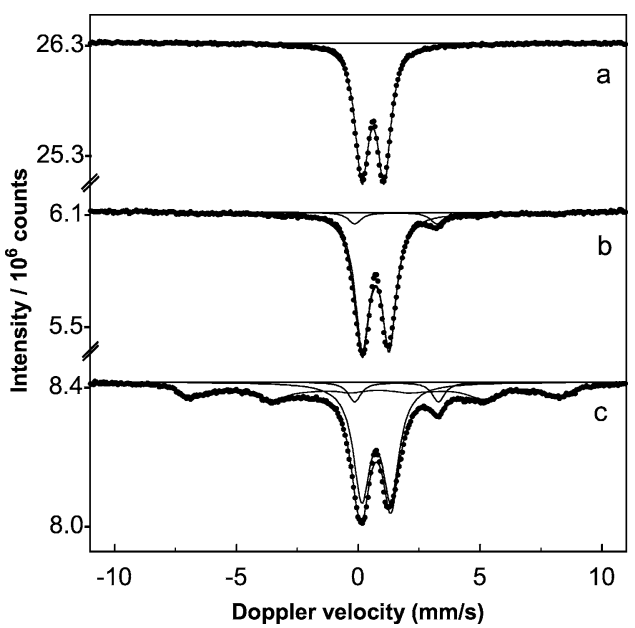

(a)

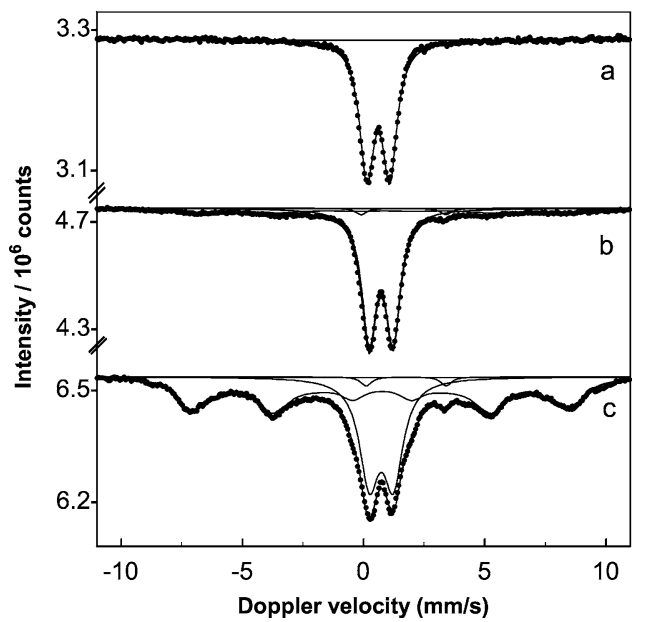

(b)

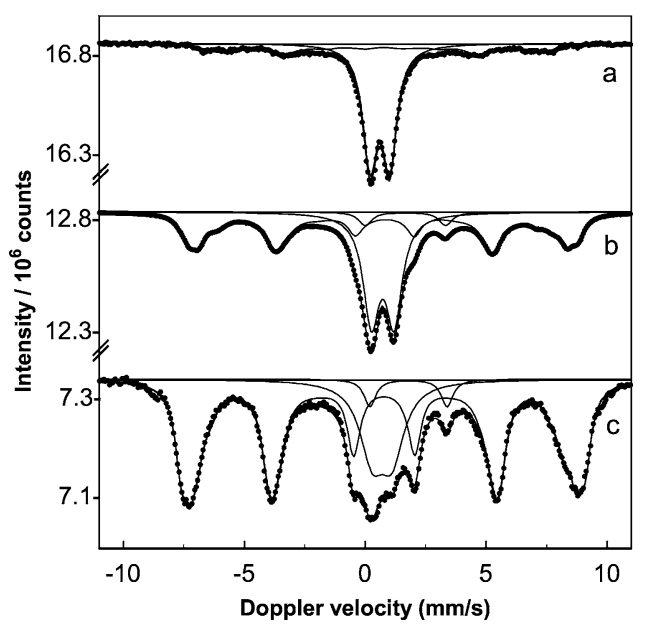

(c)

Fig. 5. ${ }^{57} \mathrm{Fe}$ Mössbauer spectra recorded in $\mathrm{He}$ at $300 \mathrm{~K}$ (lines a), $77 \mathrm{~K}$ (lines b) and $4.2 \mathrm{~K}$ (lines c): (a) Fe/ZSM5-17- $\mathrm{H}_{2} \mathrm{O}$; (b) Fe/ZSM5-17-mc; (c) Fe/ZSM5-17-sc.

are visible when comparing the Fe/ZSM5-17-mc spectra recorded at 300 and $77 \mathrm{~K}$ ( $\mathrm{a}$ and $\mathrm{b}$ ) with those of the $\mathrm{Fe} / \mathrm{ZSM} 5-17-\mathrm{H}_{2} \mathrm{O}$. Nevertheless, when measuring at $4.2 \mathrm{~K}$, an increase was detected in the intensity of the sextet signal. This is ascribed to further agglomeration of Fe. The corresponding average hyperfine field at $4.2 \mathrm{~K}$ was $48.0 \mathrm{~T}$. The complete list of the hyperfine parameters of the Fe/ZSM5$17-\mathrm{mc}$ as a function of the temperature are shown in Table $3 \mathrm{~b}$.
Significant changes were detected when a severe calcination procedure was applied (Fe/ZSM5-17-sc) (Fig. 5c, Table 3c). The detection of the sextet already at room temperature is the result of the increased average size of the $\mathrm{Fe}$ containing clusters formed during the severe calcination. By lowering the temperature, the signal of the sextet increased considerably. The $\mathrm{Fe}^{2+}$ doublet became visible as well. As can be seen from spectrum $\mathrm{c}$, at $4.2 \mathrm{~K}$ the dominant component is that of the sextet $(\mathrm{HF}=50.0 \mathrm{~T})$. When comparing

\begin{tabular}{|c|c|c|c|c|c|}
\hline Conditions & $\begin{array}{l}\text { Isomer shift } \\
(\mathrm{mm} / \mathrm{s})\end{array}$ & $\begin{array}{c}\text { Quadrupole splitting } \\
(\mathrm{mm} / \mathrm{s})\end{array}$ & $\begin{array}{l}\text { Hyperfine field } \\
\text { (T) }\end{array}$ & $\begin{array}{c}\text { Relative intensity } \\
(\%)\end{array}$ & Identification \\
\hline $300 \mathrm{~K}, \mathrm{He}$ & 0.61 & 1.02 & - & 100 & Doublet, Fe(III) \\
\hline $77 \mathrm{~K}, \mathrm{He}$ & $\begin{array}{l}0.72 \\
1.55\end{array}$ & $\begin{array}{l}1.10 \\
3.37\end{array}$ & $\begin{array}{l}- \\
-\end{array}$ & $\begin{array}{r}92 \\
8\end{array}$ & $\begin{array}{l}\text { Doublet, } \mathrm{Fe}(\mathrm{III}) \\
\text { Doublet, } \mathrm{Fe}(\mathrm{II})\end{array}$ \\
\hline $4.2 \mathrm{~K}, \mathrm{He}$ & $\begin{array}{l}0.74 \\
1.58 \\
0.78\end{array}$ & $\begin{array}{c}1.19 \\
3.44 \\
-\end{array}$ & $\begin{array}{c}- \\
- \\
46.7\end{array}$ & $\begin{array}{r}53 \\
8 \\
39\end{array}$ & $\begin{array}{l}\text { Doublet, } \mathrm{Fe}(\mathrm{III}) \\
\text { Doublet, } \mathrm{Fe}(\mathrm{II}) \\
\text { Sextet, } \mathrm{Fe}(\mathrm{III})\end{array}$ \\
\hline
\end{tabular}


Table 3b

${ }^{57} \mathrm{Fe}$ Mössbauer hyperfine parameters and relative integrated intensities of the iron species in Fe/ZSM5-17-mc

\begin{tabular}{lccccl}
\hline Conditions & $\begin{array}{c}\text { Isomer shift } \\
(\mathrm{mm} / \mathrm{s})\end{array}$ & $\begin{array}{c}\text { Quadrupole splitting } \\
(\mathrm{mm} / \mathrm{s})\end{array}$ & $\begin{array}{c}\text { Hyperfine field } \\
(\mathrm{T})\end{array}$ & $\begin{array}{c}\text { Relative intensity } \\
(\%)\end{array}$ & Identification \\
\hline $300 \mathrm{~K}, \mathrm{He}$ & 0.61 & 0.94 & - & 100 & Doublet, $\mathrm{Fe}(\mathrm{III})$ \\
$77 \mathrm{~K}, \mathrm{He}$ & 0.73 & 0.99 & - & 76 & Doublet, $\mathrm{Fe}(\mathrm{III})$ \\
& 1.65 & 3.49 & - & 3 & Doublet, $\mathrm{Fe}(\mathrm{II})$ \\
& 0.79 & & 46.6 & 21 & Sextet, $\mathrm{Fe}(\mathrm{III})$ \\
$4.2 \mathrm{~K}, \mathrm{He}$ & 0.73 & 0.99 & - & 41 & Doublet, $\mathrm{Fe}(\mathrm{III})$ \\
& 1.76 & 3.30 & - & 2 & Doublet, $\mathrm{Fe}(\mathrm{II})$ \\
& 0.73 & - & 48.0 & 57 & Sextet, $\mathrm{Fe}$ (III) \\
\hline
\end{tabular}

the present spectrum with spectra $\mathrm{c}$ recorded at $4.2 \mathrm{~K}$ on the washed and on the mildly calcined samples, the sextet appears enhanced and significantly sharper. This is ascribed to a higher concentration and a higher average size of the agglomerated Fe-containing phase caused by the severe calcination procedure.

\section{7. ${ }^{27}$ Al MAS NMR, Al K-edge XAFS}

${ }^{27} \mathrm{Al}$ MAS NMR spectroscopy was carried out on the original zeolite provided by Zeolyst $\left(\mathrm{NH}_{4} / \mathrm{ZSM} 5-17\right)$ and on its acidic form (H/ZSM5-17) obtained by calcination. The spectra are reported in Fig. 6. For both samples a dominating resonance was detected at $55 \mathrm{ppm}$, attributed to tetrahedrally coordinated framework $\mathrm{Al}$ atoms [52]. The shape of the resonance is asymmetric. This is ascribed to variations in the chemical shift arising from the $\mathrm{Si}-\mathrm{O}-\mathrm{Al}$ angles of the different crystallographic $\mathrm{T}$ sites. An additional signal was recorded at $0 \mathrm{ppm}$ and is assigned to octahedrally coordinated extra-framework Al. While in the $\mathrm{NH}_{4} / \mathrm{ZSM} 5$ this peak was present as a hardly visible weak broad component, its intensity increased upon calcination to about $7 \%$ of the total aluminum. The existence of octahedrally coordinated aluminum attached to the framework has frequently been reported for acidic zeolites [53].

Al K-edge XANES spectra of the support $\left(\mathrm{NH}_{4} / \mathrm{ZSM} 5-\right.$ 17, H/ZSM5-17) and of the over-exchanged Fe/ZSM5-17 after severe calcination (Fe/ZSM5-17-sc) are depicted in Fig. 7. As can be seen in this picture, all spectra overlap, pointing to an identical aluminum coordination in all the samples. A sharp whiteline is visible, followed by a fine structure in the region 4-11 eV above the edge (1569$1576 \mathrm{eV})$. A broad peak is also present, centered at around $20 \mathrm{eV}$ above the edge $(1584 \mathrm{eV})$. These features are typical of tetrahedrally coordinated aluminum [26]. The octahedrally coordinated aluminum, measured by ${ }^{27} \mathrm{Al}$ MAS NMR in H/ZSM5-17 is not visible in the Al K-edge spectra. This is ascribed to the differences in the measurements conditions, i.e., high vacuum (Al XAS) versus strongly hydrated state $\left({ }^{27} \mathrm{Al}\right.$ MAS NMR). When water is removed from the pores of the zeolite, only tetrahedral aluminum is present [28]. From the results presented it is concluded that no significant changes occurred to the aluminum coordination during the synthesis, even after applying a severe calcination procedure.

\subsection{Fe K-edge HR-XANES}

Figure 8 shows the normalized high-resolution fluorescence pre-edge spectrum of the hematite reference and its calculated deconvolution peaks. Four different contributions are visible. Peaks 1 and 2, centered respectively at 7112.65 and $7114.05 \mathrm{eV}$, are related to $1 s \rightarrow 3 d$ (quadrupolar) and/or $1 s \rightarrow 4 p$ (dipolar) metal electronic transitions [35,54,55]. Contributions 3 and 4 centered above $7115.0 \mathrm{eV}$ (7115.34 and $7116.88 \mathrm{eV}$ ) are due to extra transitions involving $3 d$ orbitals of distant iron neighbors [35]. Contributions 3 and 4 were not included in the determination of the reference preedge area and centroid position. The pre-edge area and the centroid position of the hematite reference were used as standard to analyze the data of the Fe/ZSM-5 samples [34].

Table 3c

${ }^{57} \mathrm{Fe}$ Mössbauer hyperfine parameters and relative integrated intensities of the iron species in Fe/ZSM5-17-sc

\begin{tabular}{|c|c|c|c|c|c|}
\hline Conditions & $\begin{array}{l}\text { Isomer shift } \\
(\mathrm{mm} / \mathrm{s})\end{array}$ & $\begin{array}{c}\text { Quadrupole splitting } \\
(\mathrm{mm} / \mathrm{s})\end{array}$ & $\begin{array}{l}\text { Hyperfine field } \\
\text { (T) }\end{array}$ & $\begin{array}{l}\text { Relative intensity } \\
(\%)\end{array}$ & Identification \\
\hline $300 \mathrm{~K}, \mathrm{He}$ & $\begin{array}{l}0.62 \\
0.59\end{array}$ & 0.83 & $\begin{array}{c}- \\
40.7\end{array}$ & $\begin{array}{l}69 \\
31\end{array}$ & Doublet, Fe(III) \\
\hline $77 \mathrm{~K}, \mathrm{He}$ & $\begin{array}{l}0.72 \\
1.66 \\
0.75\end{array}$ & $\begin{array}{l}0.94 \\
3.34\end{array}$ & $\begin{array}{c}- \\
- \\
48.6\end{array}$ & $\begin{array}{r}41 \\
4 \\
55\end{array}$ & $\begin{array}{l}\text { Doublet, Fe(III) } \\
\text { Doublet, Fe(II) } \\
\text { Sextet, Fe(III) }\end{array}$ \\
\hline $4.2 \mathrm{~K}, \mathrm{He}$ & $\begin{array}{l}0.70 \\
1.79 \\
0.76\end{array}$ & $\begin{array}{c}0.82 \\
3.19 \\
-\end{array}$ & $\begin{array}{l}- \\
- \\
50.0\end{array}$ & $\begin{array}{r}21 \\
4 \\
75\end{array}$ & $\begin{array}{l}\text { Doublet, } \mathrm{Fe}(\mathrm{III}) \\
\text { Doublet, } \mathrm{Fe}(\mathrm{II}) \\
\text { Sextet, } \mathrm{Fe}(\mathrm{III})\end{array}$ \\
\hline
\end{tabular}




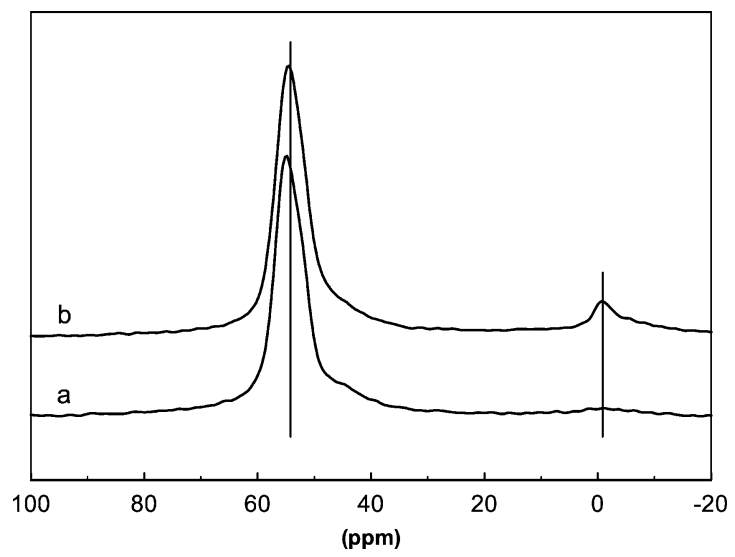

Fig. $6 .{ }^{27} \mathrm{Al}$ MAS NMR spectra of $\mathrm{NH}_{4} / \mathrm{ZSM} 5-17$ (a) and H/ZSM5-17 (b).

In Fig. 9 the experimental normalized pre-edge spectra of the Fe/ZSM5 samples are presented together with that of hematite. The Fe K pre-edges of all samples are significantly different from that of the reference oxide. They hardly show contributions centered at high energy ( $>7115.0 \mathrm{eV})$, ascribable to distant $\mathrm{Fe}$ neighbors. When comparing the pre-edges of the calcined samples (Fe/ZSM5-17-mc and $\mathrm{Fe} / \mathrm{ZSM} 5-17-\mathrm{sc}$ ) with that of $\mathrm{Fe} / \mathrm{ZSM} 5-17-\mathrm{H}_{2} \mathrm{O}$, only minor changes are visible. After calcination the overall height appears to be slightly decreased and some tailing are visible at around $7116 \mathrm{eV}$. This contribution, more evident in the severely calcined sample (Fe/ZSM5-17-sc), can be attributed to agglomeration processes of iron occurred during calcination. The pre-edge features of the measured samples are collected in Table 4, together with that of averaged $\mathrm{Fe}(\mathrm{II})$ and $\mathrm{Fe}$ (III) reference materials with known coordination and geometry, obtained from the literature [34]. Typically, a separation of $1.4 \pm 0.1 \mathrm{eV}$ is present in the preedge centroid position of $\mathrm{Fe}(\mathrm{II})(7112.1 \mathrm{eV})$ and $\mathrm{Fe}(\mathrm{III})$ $(7113.5 \mathrm{eV})$ compounds, irrespective to their coordination. On the contrary, the pre-edge area is depending on both the oxidation state and the geometry of the iron coordination. As appears in Table 4, the centroid position of the pre-edges of

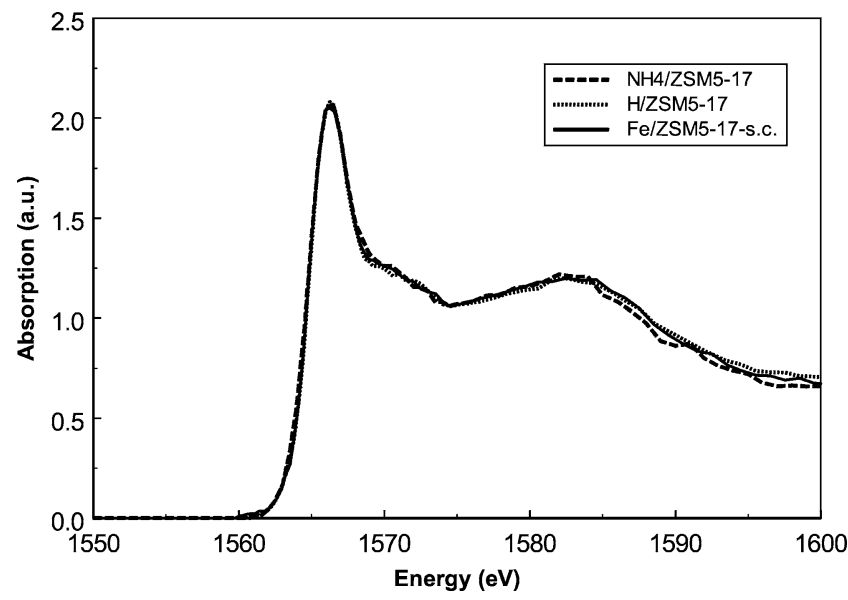

Fig. 7. XAS Al K-edge spectra of $\mathrm{NH}_{4}$ /ZSM5-17, H/ZSM5-17, and Fe/ ZSM5-17 sc.

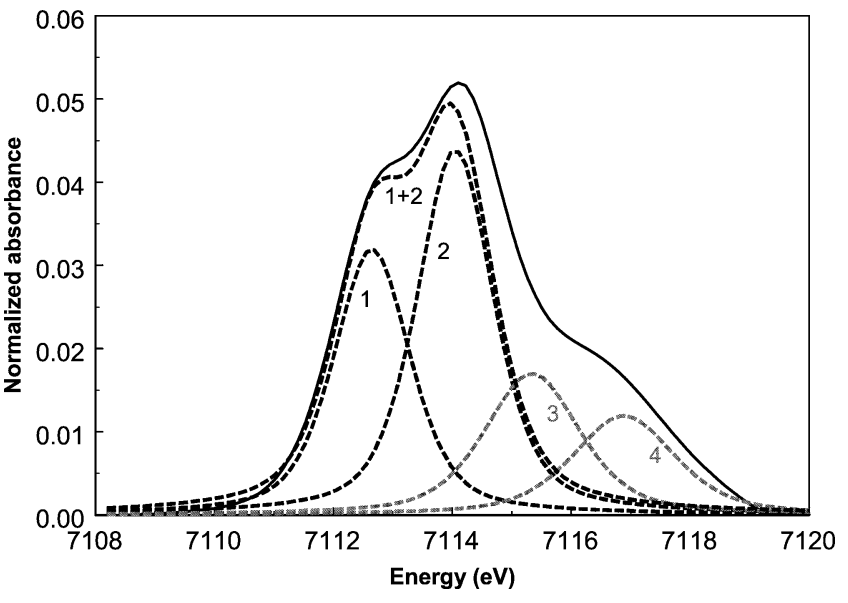

Fig. 8. Normalized high-resolution fluorescence pre-edge spectrum of hematite (measured in $\mathrm{He}$ at $30^{\circ} \mathrm{C}, 1 \mathrm{bar}$ ) and best deconvolution calculated with GRAMS.

the Fe/ZSM5 samples and of hematite corresponds, within the margin of error, to that of $\mathrm{Fe}(\mathrm{III})$ reference compounds. Furthermore, the integrated intensity of the Fe/ZSM5 preedges, which appear to be lower than that of the reference hematite, is closer to that of a perfectly symmetric octahedrally coordinated reference. It is therefore concluded that in the Fe/ZSM5 measured under ambient conditions iron is present as $\mathrm{Fe}^{3+}$ octahedra with a slightly distorted symmetry. No significant differences in the local geometry of iron was visible upon calcination.

\subsection{Fe K-edge XAFS}

In Fig. 10 the near edge (XANES) spectra of the Fe/ ZSM5 samples, are presented, together with that of the $\mathrm{Fe}$ (III) hematite reference. As can be seen, the edge position of all the Fe/ZSM5 samples, including that of Fe/ZSM5$17-\mathrm{Cl}$, corresponds to that of the reference. It is therefore concluded that, also after sublimation of $\mathrm{FeCl}_{3}$, the oxidation state of iron is $\mathrm{Fe}^{3+}$.

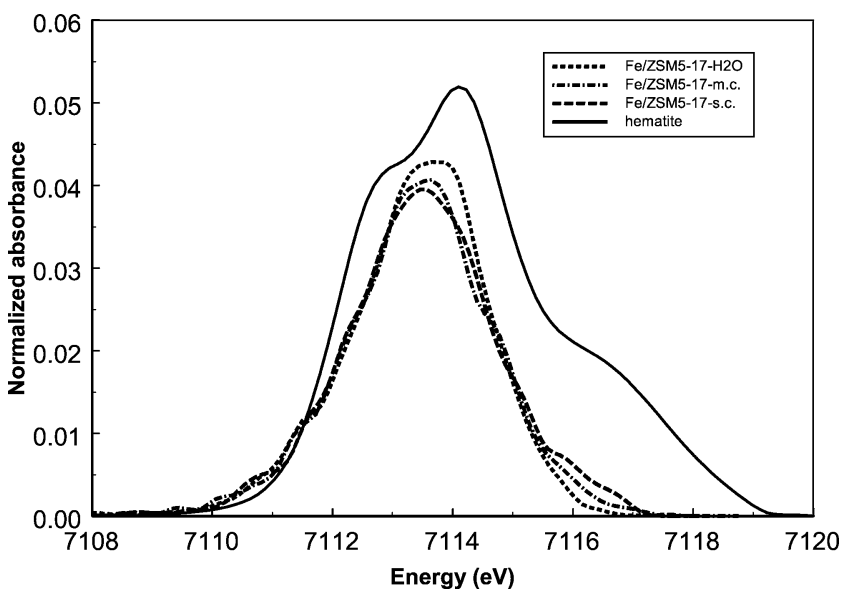

Fig. 9. Normalized high-resolution fluorescence pre-edge spectra of $\mathrm{Fe} /$ ZSM5-17- $\mathrm{H}_{2} \mathrm{O}, \mathrm{Fe} / \mathrm{ZSM} 5-17-\mathrm{mc}, \mathrm{Fe} / \mathrm{ZSM} 5-17$-sc, and hematite (measured in $\mathrm{He}$ at $30^{\circ} \mathrm{C}, 1 \mathrm{bar}$ ). 
Table 4

Pre-edge characteristics of $\mathrm{Fe} / \mathrm{ZSM} 5-17-\mathrm{H}_{2} \mathrm{O}, \quad \mathrm{Fe} / \mathrm{ZSM} 5-17-\mathrm{mc}$, $\mathrm{Fe} / \mathrm{ZSM} 5-17-\mathrm{sc}, \alpha-\mathrm{Fe}_{2} \mathrm{O}_{3}$, and reference model coordinations [34]

\begin{tabular}{lccc}
\hline Sample & $\begin{array}{c}\text { Normalized } \\
\text { height }\end{array}$ & $\begin{array}{c}\text { Total } \\
\text { area }\end{array}$ & $\begin{array}{c}\text { Centroid } \\
\text { position }(\mathrm{eV})\end{array}$ \\
\hline $\mathrm{Fe} / \mathrm{ZSM} 5-17-\mathrm{H}_{2} \mathrm{O}$ & 0.043 & 0.119 & 7113.41 \\
$\mathrm{Fe} / \mathrm{ZSM} 5-17-\mathrm{mc}$ & 0.040 & 0.120 & 7113.42 \\
$\mathrm{Fe} / \mathrm{ZSM}-17-\mathrm{sc}$ & 0.039 & 0.119 & 7113.48 \\
$\alpha-\mathrm{Fe}_{2} \mathrm{O}_{3}{ }^{\mathrm{a}}$ & 0.049 & 0.138 & 7113.50 \\
$\alpha-\mathrm{Fe}_{2} \mathrm{O}_{3}$ & 0.052 & 0.204 & 7114.29 \\
$\mathrm{Reference} \mathrm{model}$ & & Total area & Centroid \\
& & position $(\mathrm{eV})$ \\
$\mathrm{Fe}(\mathrm{II})$ in tetrahedral coordination & $0.22( \pm 0.02)$ & 7112.1 \\
$\mathrm{Fe}(\mathrm{II})$ in octahedral coordination & $0.06( \pm 0.02)$ & 7112.1 \\
$\mathrm{Fe}(\mathrm{III})$ in tetrahedral coordination & $0.34( \pm 0.02)$ & 7113.5 \\
$\mathrm{Fe}(\mathrm{III})$ in octahedral coordination & $0.08( \pm 0.02)$ & 7113.5 \\
\hline
\end{tabular}

${ }^{\text {a }}$ After substraction of spectral contributions 3 and 4 (Fig. 8).

Figure 11a shows the experimental EXAFS data of $\mathrm{Fe} / \mathrm{ZSM} 5-17-\mathrm{Cl}$. The corresponding $k^{1}$ Fourier transformed spectrum (uncorrected) is depicted in Fig. 11b, together with the best fit obtained. In the Fourier spectrum one major asymmetric peak is visible at around $1.6 \AA$, followed by a second weak contribution at $2.5 \AA$. The best fit for the major peak was obtained by using two separate shells: a $\mathrm{Fe}-\mathrm{Cl}$ and a closer $\mathrm{Fe}-\mathrm{O}$ shell. A $k^{3}$ weighing of the Fourier transform showed that the contribution at $2.5 \AA$ was ascribable to a heavy scatterer. Therefore this contribution was fitted with a $\mathrm{Fe}-\mathrm{Fe}$ shell. The total fit was further optimized by including the contribution of distant $\mathrm{O}$-neighbors, ascribable to oxygen of the zeolite lattice $\left(\mathrm{Fe}-\mathrm{O}_{z}\right)$. The results of the EXAFS analysis are collected in Table 6. These show that upon sublimation of $\mathrm{FeCl}_{3}$ the majority of the iron atoms in the $\mathrm{Fe} / \mathrm{ZSM} 5$ consist of isolated $\mathrm{Fe}^{3+}$ species. These species contain on average two chlorine atoms and are bound to the zeolite via two oxygen atoms [21]. The $\mathrm{Fe}-\mathrm{Fe}$ contribution, however, suggests that a minor fraction of iron

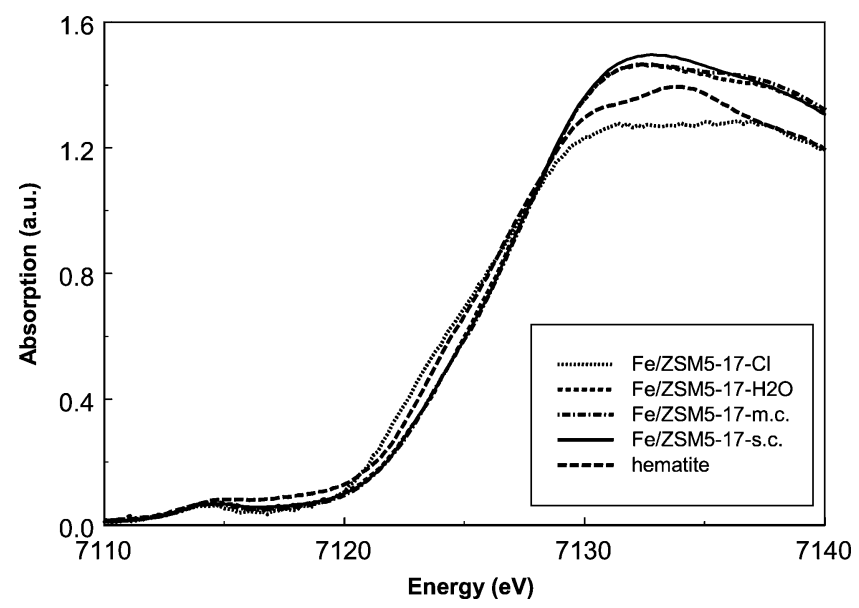

Fig. 10. Normalized XANES spectra of Fe/ZSM5-17-Cl, Fe/ZSM5-17$\mathrm{H}_{2} \mathrm{O}, \mathrm{Fe}$ /ZSM5-17-mc, Fe/ZSM5-17-sc, and hematite (measured in $\mathrm{He}$ at $77 \mathrm{~K})$.

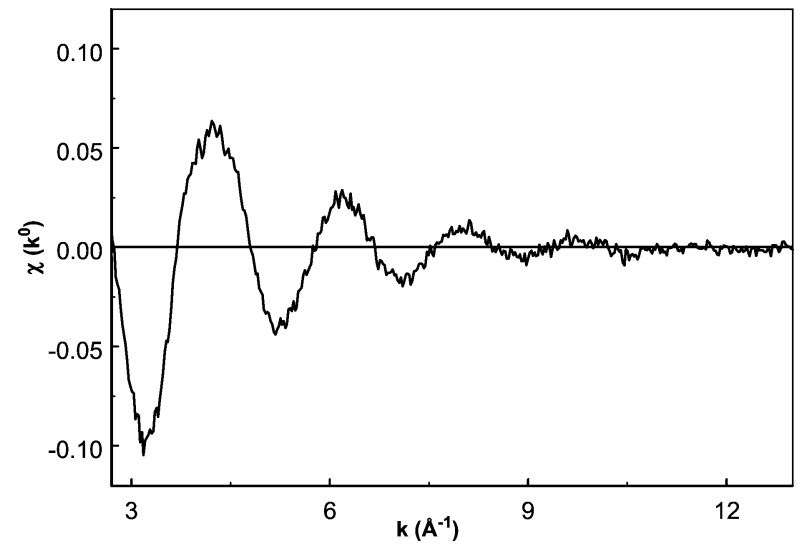

(a)

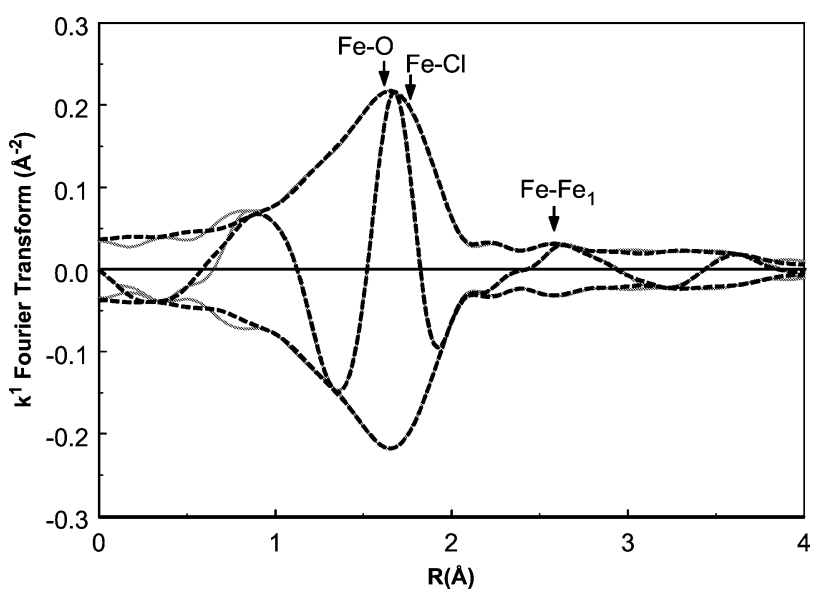

(b)

Fig. 11. (a) $\chi\left(k^{0}\right)$ experimental data of Fe/ZSM5-17-Cl, measured in $\mathrm{He}$ at $77 \mathrm{~K}$. (b) $k^{1}$ Fourier transformed experimental (gray solid line) and fitted (black dotted line, $R=1-4 \AA, \Delta k=2.7-13.0$ ) data of Fe/ZSM5-17-Cl, measured in $\mathrm{He}$ at $77 \mathrm{~K}$.

is present, already at this stage of the synthesis, as binuclear or oligomeric chlorinated Fe complexes.

The EXAFS data of the Fe/ZSM5 after washing are plotted in Fig. 12a. The $k^{1}$ Fourier transformation is presented together with the best total fit in Fig. 12b. A very broad peak is present in the Fourier transform of the Fe/ZSM5-17- $\mathrm{H}_{2} \mathrm{O}$ at $1.5 \AA$ ( $\downarrow \mathrm{Fe}-\mathrm{O}$ in the picture), together with a second one at around $2.5 \AA\left(\downarrow \mathrm{Fe}-\mathrm{Fe}_{1}\right)$. No satisfactory fit could be obtained by using a $\mathrm{Fe}-\mathrm{Cl}$ contribution. The peak at $1.5 \AA$ was therefore entirely fitted with the $\mathrm{Fe}-\mathrm{O}$ reference. The analysis of this contribution was performed on the basis of the information obtained by the HR-XANES experiments, i.e., a total amount of six oxygen neighbors was always fitted. Different possibilities for the distribution of the six oxygen neighbors were explored, i.e., two separate $\mathrm{Fe}-\mathrm{O}$ shells with a $2: 4$ or a $3: 3$ oxygen distribution and three separate $\mathrm{Fe}-\mathrm{O}$ shells with a $2: 2: 2$ distribution (Table 5). Even though all the models present acceptable statistics, the best fit could be obtained with the models $2: 2: 2$ and $3: 3$. The second peak of the Fourier transform $\left(\downarrow \mathrm{Fe}-\mathrm{Fe}_{1}\right.$, Fig. 12b) could be satisfactorily fitted with one single $\mathrm{Fe}-\mathrm{Fe}$ shell centered 


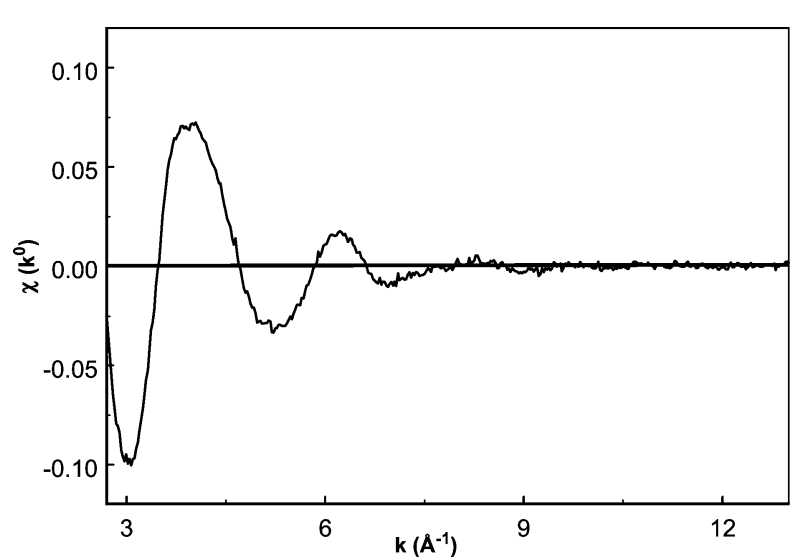

(a)

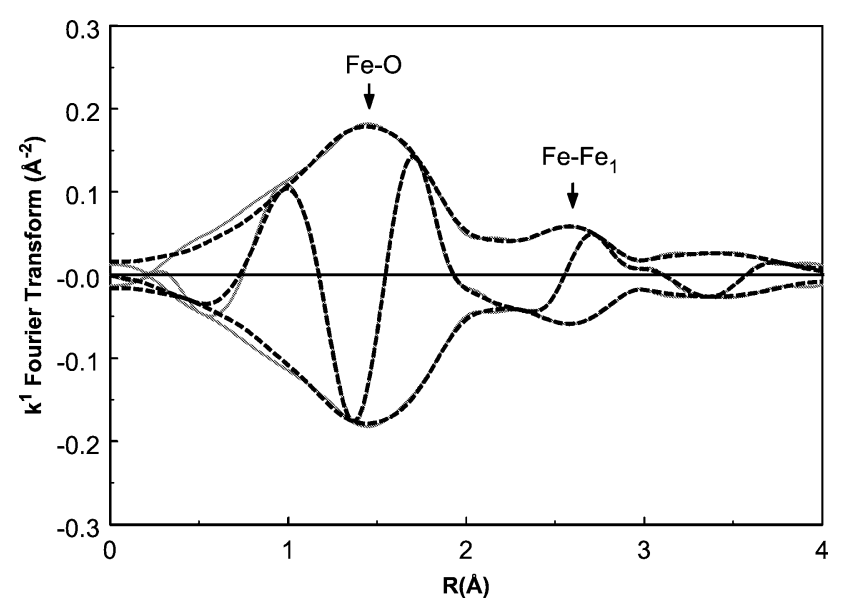

(b)

Fig. 12. (a) $\chi\left(k^{0}\right)$ experimental data of Fe/ZSM5-17- $\mathrm{H}_{2} \mathrm{O}$, measured in $\mathrm{He}$ at $77 \mathrm{~K}$. (b) $k^{1}$ Fourier transformed experimental (gray solid line) and fitted (black dotted line, $R=1-4 \AA, \Delta k=2.7-13.0$ ) data of Fe/ZSM5-17- $\mathrm{H}_{2} \mathrm{O}$, measured in $\mathrm{He}$ at $77 \mathrm{~K}$. at $3.05 \AA$. Also for the washed sample oxygen from the lattice was fitted at higher distance $\left(\mathrm{Fe}-\mathrm{O}_{z}\right)$. As can be seen from Table 5, in Fe/ZSM5-17- $\mathrm{H}_{2} \mathrm{O}$ iron is organized in binuclear Fe-clusters (Fe-Fe coordination is 1.0).

Figure 13a shows the EXAFS of the Fe/ZSM5 after the mild calcination. The corresponding $k^{1}$ Fourier transformation is presented together with the best total fit in Fig. 13b. By comparing Figs. $12 \mathrm{~b}$ and $13 \mathrm{~b}$ it is evident that the Fourier transform of the mildly calcined sample resembles very closely that of the sample after washing. Minor changes are visible in the imaginary part of the Fourier transformation at $3.0 \AA$. The same procedure used for the Fe/ZSM5-17$\mathrm{H}_{2} \mathrm{O}$ was applied for fitting the distribution of the oxygen atoms in this sample. Also for the mildly calcined sample the best fit could be obtained with both the $3: 3$ and the $2: 2: 2$ models, i.e., with a symmetrical distribution of the six oxygen atoms in two or three separate $\mathrm{Fe}-\mathrm{O}$ shells. The EXAFS coordination parameters for the model $3: 3$ (this model is chosen since it makes use of less free parameters than the $2: 2: 2$ ) are summarized in Table 6 . Slight changes were revealed in the $\mathrm{Fe}-\mathrm{Fe}$ contribution. The use of a single $\mathrm{Fe}-\mathrm{Fe}$ shell could not produce a satisfactory fit. A second shell had to be introduced ( $\downarrow \mathrm{Fe}-\mathrm{Fe}_{2}$ in Fig. 13b). The CN of the $\mathrm{Fe}-\mathrm{Fe}_{1}$ shell is increased to 1.2. Furthermore a second $\mathrm{Fe}-\mathrm{Fe}$ shell $\left(\mathrm{Fe}-\mathrm{Fe}_{2}\right)$ with a $\mathrm{CN}$ of 0.4 appears at higher distance. These changes are ascribed to further agglomeration of iron. The statistical significance of the fitted $\mathrm{Fe}-\mathrm{Fe}_{2}$ shell was confirmed by the comparison between the noise level present in the experimental data with the amplitude of the chi function produced by only this contribution $\left(\mathrm{Fe}-\mathrm{Fe}_{2}\right.$, Fig. 13c).

The EXAFS data of the Fe/ZSM5-sc are displayed in Fig. 14a. The $k^{1}$ Fourier transformation and the best total fit obtained are presented in Fig. 14b. The large $\mathrm{Fe}-\mathrm{O}$ peak at $1.5 \AA$ does not show any differences when compared to the corresponding one in the washed and the mild

Table 5

Fits of different models obtained by multiple shells analysis of the EXAFS data: Fe/ZSM5-17- $\mathrm{H}_{2} \mathrm{O}$

\begin{tabular}{|c|c|c|c|c|c|c|}
\hline \multirow[t]{2}{*}{ Shells } & \multirow{2}{*}{$\begin{array}{c}N \\
( \pm 10 \%)\end{array}$} & \multirow{2}{*}{$\begin{array}{l}R(\AA) \\
( \pm 1 \%)\end{array}$} & \multirow{2}{*}{$\begin{array}{c}\Delta \sigma^{2}\left(10^{-3} \AA^{2}\right) \\
( \pm 5 \%)\end{array}$} & \multirow{2}{*}{$\begin{array}{c}\Delta E_{0}(\mathrm{eV}) \\
( \pm 10 \%)\end{array}$} & \multicolumn{2}{|c|}{$k^{1}$-variance $(\%)$} \\
\hline & & & & & Im. part & Abs. part \\
\hline $\mathrm{Fe} /$ ZSM5-17- $\mathrm{H}_{2} \mathrm{O}(\operatorname{model} 2: 4)$ & & & & & 0.33 & 0.17 \\
\hline $\mathrm{Fe}-\mathrm{O}_{1}$ & 2.1 & 1.93 & 6.5 & 12.0 & & \\
\hline $\mathrm{Fe}-\mathrm{O}_{2}$ & 4.0 & 2.03 & 8.7 & -6.5 & & \\
\hline $\mathrm{Fe}-\mathrm{Fe}_{1}$ & 1.0 & 3.03 & 1.1 & 0.5 & & \\
\hline $\mathrm{Fe}-\mathrm{O}_{z}$ & 4.8 & 4.18 & 11.4 & -8.8 & & \\
\hline $\mathrm{Fe} / \mathrm{ZSM} 5-17-\mathrm{H}_{2} \mathrm{O}(\operatorname{model} 2: 2: 2)$ & & & & & 0.13 & 0.07 \\
\hline $\mathrm{Fe}-\mathrm{O}_{1}$ & 1.9 & 1.85 & 0.5 & 7.2 & & \\
\hline $\mathrm{Fe}-\mathrm{O}_{2}$ & 2.0 & 1.99 & 0.1 & 11.1 & & \\
\hline $\mathrm{Fe}-\mathrm{O}_{3}$ & 2.1 & 2.09 & 3.0 & -10.5 & & \\
\hline $\mathrm{Fe}-\mathrm{Fe}_{1}$ & 1.0 & 3.05 & 0.8 & -2.5 & & \\
\hline $\mathrm{Fe}-\mathrm{O}_{z}$ & 4.5 & 4.02 & 9.4 & -3.0 & & \\
\hline $\mathrm{Fe} / \mathrm{ZSM} 5-17-\mathrm{H}_{2} \mathrm{O}(\operatorname{model} 3: 3$ ) & & & & & 0.13 & 0.08 \\
\hline $\mathrm{Fe}-\mathrm{O}_{1}$ & 3.1 & 1.91 & 9.1 & 12.0 & & \\
\hline $\mathrm{Fe}-\mathrm{O}_{2}$ & 3.0 & 2.05 & 5.9 & -8.1 & & \\
\hline $\mathrm{Fe}-\mathrm{Fe}_{1}$ & 1.0 & 3.05 & 0.7 & -3.0 & & \\
\hline $\mathrm{Fe}-\mathrm{O}_{z}$ & 4.4 & 3.99 & 10.5 & -1.9 & & \\
\hline
\end{tabular}




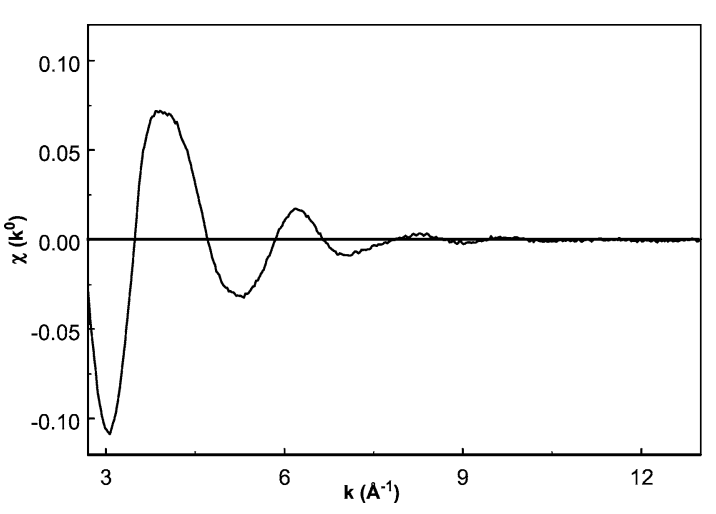

(a)

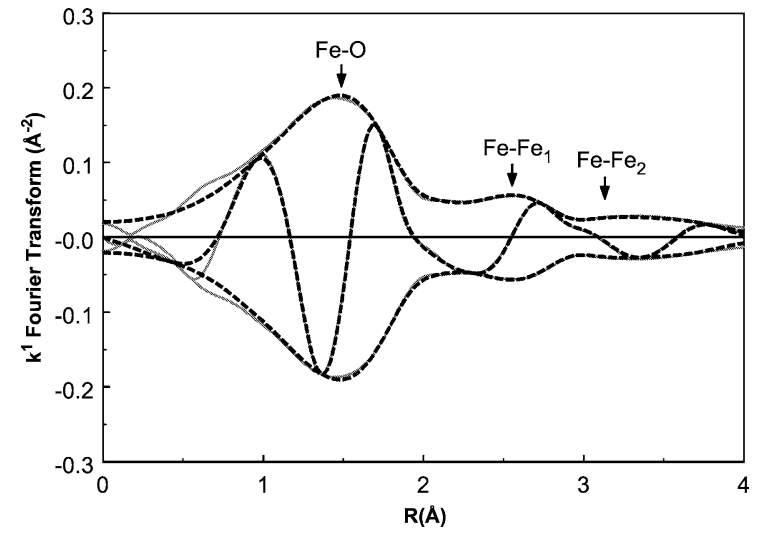

(b)

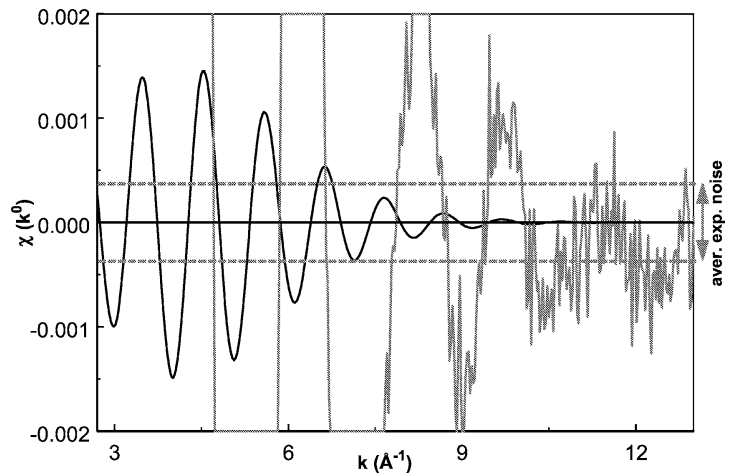

(c)

Fig. 13. (a) $\chi\left(k^{0}\right)$ experimental data of Fe/ZSM5-17-mc, measured in He at $77 \mathrm{~K}$. (b) $k^{1}$ Fourier transformed experimental (gray solid line) and fitted (black dotted line, $R=1-4 \AA, \Delta k=2.7-13.0$ ) data of Fe/ZSM5-17-mc, measured in He at $77 \mathrm{~K}$. (c) Comparison between the average noise level in the experimental data of $\mathrm{Fe} / \mathrm{ZSM} 5-17-\mathrm{mc}$ (see (a)) and the amplitude of the fitted $\mathrm{Fe}_{-}-\mathrm{Fe}_{2}$ contribution (see Table 6); fitted $\mathrm{Fe}-\mathrm{Fe}_{2} \chi\left(k^{0}\right.$ ), solid black line; experimental $\mathrm{Fe} / \mathrm{ZSM} 5-17-\mathrm{mc} \chi\left(k^{0}\right)$, gray solid line.

Table 6

Best fits obtained by multiple shells analysis of the EXAFS data: Fe/ZSM5-17-Cl, Fe/ZSM5-17- $\mathrm{H}_{2} \mathrm{O}, \mathrm{Fe} / \mathrm{ZSM} 5-17-\mathrm{mc}$, and Fe/ZSM5-17-sc

\begin{tabular}{|c|c|c|c|c|c|c|}
\hline \multirow[t]{2}{*}{ Shells } & \multirow{2}{*}{$\begin{array}{c}N \\
( \pm 10 \%)\end{array}$} & \multirow{2}{*}{$\begin{array}{l}R(\AA) \\
( \pm 1 \%)\end{array}$} & \multirow{2}{*}{$\begin{array}{c}\Delta \sigma^{2}\left(10^{-3} \AA^{2}\right) \\
( \pm 5 \%)\end{array}$} & \multirow{2}{*}{$\begin{array}{c}\Delta E_{0}(\mathrm{eV}) \\
( \pm 10 \%)\end{array}$} & \multicolumn{2}{|c|}{$k^{1}$-variance $(\%)$} \\
\hline & & & & & Im. part & Abs. part \\
\hline$\overline{\mathrm{Fe} / Z S M 5-17-\mathrm{Cl}}$ & & & & & 0.08 & 0.04 \\
\hline $\mathrm{Fe}-\mathrm{O}$ & 1.8 & 1.99 & -1.0 & -5.9 & & \\
\hline $\mathrm{Fe}-\mathrm{Cl}$ & 2.1 & 2.20 & 1.4 & 4.5 & & \\
\hline $\mathrm{Fe}-\mathrm{Fe}$ & 0.3 & 2.94 & 0.0 & 8.5 & & \\
\hline $\mathrm{Fe}-\mathrm{O}_{z}$ & 4.4 & 3.97 & 10.5 & -5.5 & & \\
\hline $\mathrm{Fe} /$ ZSM5-17- $\mathrm{H}_{2} \mathrm{O}$ (model $3: 3$ ) & & & & & 0.13 & 0.08 \\
\hline $\mathrm{Fe}-\mathrm{O}_{1}$ & 3.1 & 1.91 & 9.1 & 12.0 & & \\
\hline $\mathrm{Fe}-\mathrm{O}_{2}$ & 3.0 & 2.05 & 5.9 & -8.1 & & \\
\hline $\mathrm{Fe}-\mathrm{Fe}_{1}$ & 1.0 & 3.05 & 0.7 & -3.0 & & \\
\hline $\mathrm{Fe}-\mathrm{O}_{z}$ & 4.4 & 3.99 & 10.5 & -1.9 & & \\
\hline Fe/ZSM5-17-mc (model $3: 3$ ) & & & & & 0.10 & 0.06 \\
\hline $\mathrm{Fe}-\mathrm{O}_{1}$ & 3.0 & 1.90 & 9.6 & 12.0 & & \\
\hline $\mathrm{Fe}-\mathrm{O}_{2}$ & 3.1 & 2.04 & 4.3 & -7.3 & & \\
\hline $\mathrm{Fe}-\mathrm{Fe}_{1}$ & 1.2 & 3.06 & 5.4 & -3.6 & & \\
\hline $\mathrm{Fe}-\mathrm{Fe}_{2}$ & 0.4 & 3.40 & 10.7 & -8.0 & & \\
\hline $\mathrm{Fe}-\mathrm{O}_{z}$ & 4.7 & 4.11 & 11.7 & -6.6 & & \\
\hline Fe/ZSM5-17-sc (model 3:3) & & & & & 0.25 & 0.12 \\
\hline $\mathrm{Fe}-\mathrm{O}_{1}$ & 3.0 & 1.90 & 8.1 & 12.0 & & \\
\hline $\mathrm{Fe}-\mathrm{O}_{2}$ & 3.1 & 2.04 & 6.9 & -7.2 & & \\
\hline $\mathrm{Fe}-\mathrm{Fe}_{1}$ & 1.6 & 3.03 & 2.0 & -4.3 & & \\
\hline $\mathrm{Fe}-\mathrm{Fe}_{2}$ & 1.3 & 3.42 & 8.5 & -8.5 & & \\
\hline $\mathrm{Fe}-\mathrm{O}_{z}$ & 4.8 & 4.18 & 11.2 & -8.9 & & \\
\hline
\end{tabular}




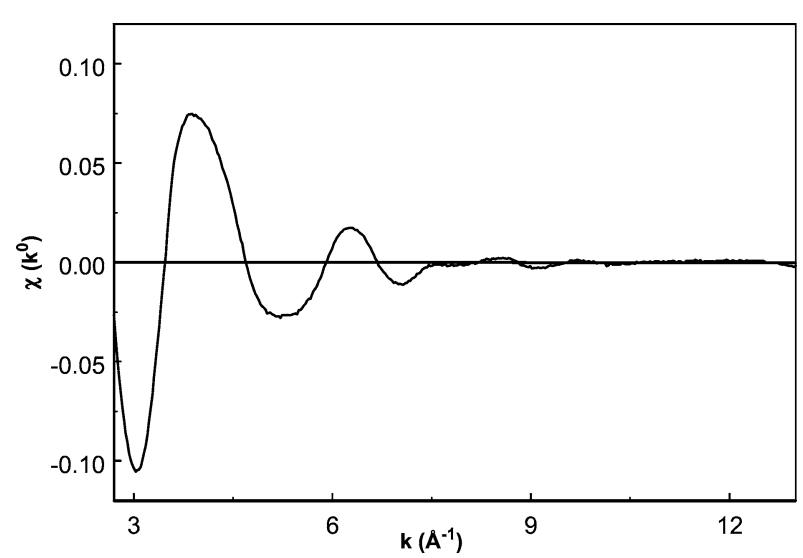

(a)

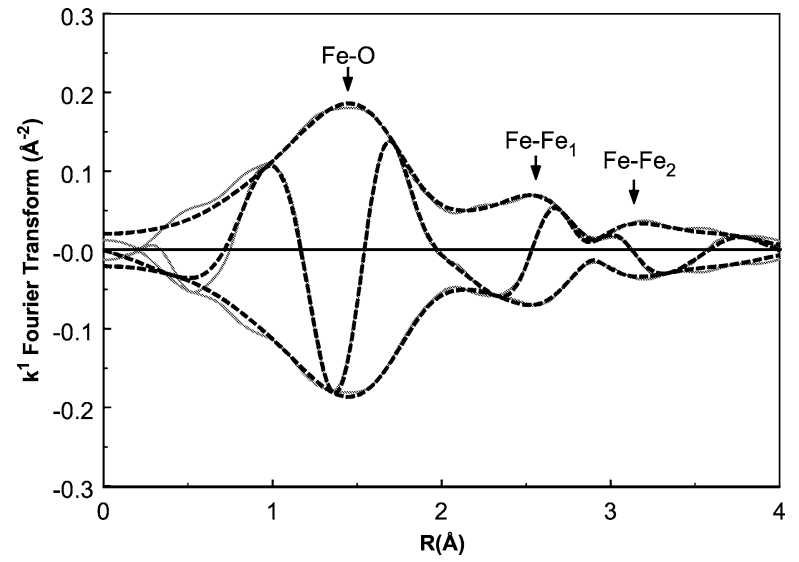

(b)

Fig. 14. (a) $\chi\left(k^{0}\right)$ experimental data of Fe/ZSM5-17-sc, measured in He at 77 K. (b) $k^{1}$ Fourier transformed experimental (gray solid line) and fitted (black dotted line, $R=1-4 \AA, \Delta k=2.7-13.0$ ) data of Fe/ZSM5-17-sc, measured in He at $77 \mathrm{~K}$.

calcined samples. On the opposite, significant changes are visible in both the real and the imaginary part of the $\mathrm{Fe}-$ $\mathrm{Fe}$ shells. For an easier comparison the Fourier transforms of the washed and of the differently calcined samples are presented together in Fig. 15. On the Fe/ZSM5 sample upon severe calcination an increase is clearly visible in the intensity of the real part of the $\mathrm{Fe}-\mathrm{Fe}_{1}$ shell, together with a minor shift of the imaginary part towards a shorter distance. At the same time, the contribution of the second $\mathrm{Fe}-\mathrm{Fe}$ shell $\left(\mathrm{Fe}-\mathrm{Fe}_{2}\right)$ becomes significantly better resolved and increased in intensity as well. The EXAFS coordination parameters for model $3: 3$ are collected in Table 6 . The increase of the $\mathrm{Fe}-\mathrm{Fe}$ coordination numbers of both $\mathrm{Fe}-\mathrm{Fe}$ shells after severe calcination is consistent with a significant formation of $\mathrm{Fe}$ clusters. Nevertheless, clear differences are still present in the local coordination of iron between the severely calcined sample and the hematite reference (Fig. 16).

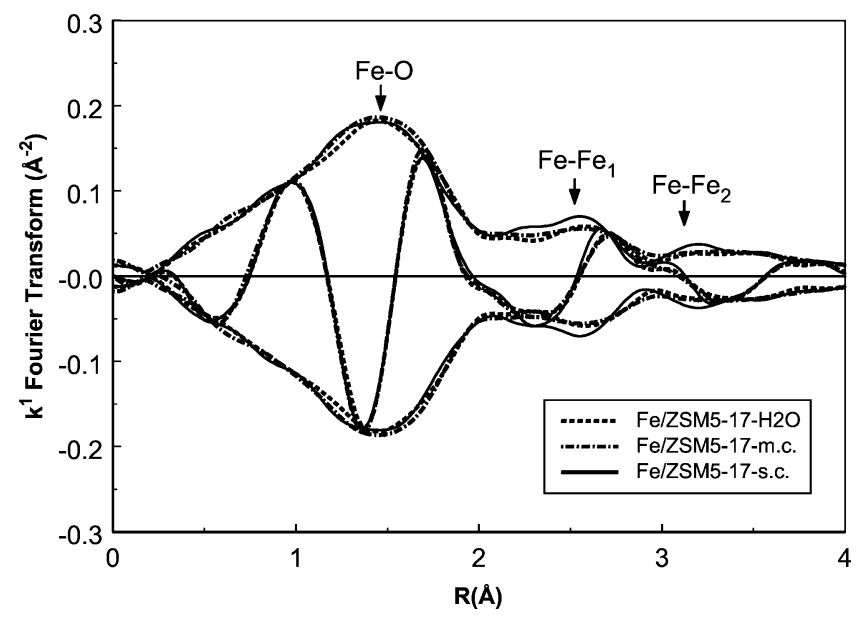

Fig. 15. $k^{1}$ Fourier transformed experimental EXAFS data of $\mathrm{Fe} /$ ZSM5-17- $\mathrm{H}_{2} \mathrm{O}, \mathrm{Fe} / \mathrm{ZSM} 5-17-\mathrm{mc}$, and $\mathrm{Fe} / \mathrm{ZSM} 5-17$-sc, measured in $\mathrm{He}$ at $77 \mathrm{~K}(\Delta k=2.7-13.0)$.

\section{Discussion}

\subsection{Sublimation of $\mathrm{FeCl}_{3}$}

The EXAFS fit of the sample after $\mathrm{FeCl}_{3}$ sublimation revealed that the majority of the Fe species formed upon reaction with the Brønsted sites are mononuclear (Table 6) [21]. They consist of isolated tetrahedral $\mathrm{Fe}^{3+}$, attached to the zeolite matrix via two oxygen atoms located at the same distance. The charge of iron is further balanced by two chlorine atoms. The detection of a minor $\mathrm{Fe}-\mathrm{Fe}$ scattering ( $\mathrm{Fe}-\mathrm{Fe} \mathrm{CN}=0.3$ ), can be ascribed to the presence, already at this stage of the synthesis, of Fe binuclear clusters or $\mathrm{Fe}$ species with a higher nuclearity. The presence of such species was revealed by an in situ ESR study by Kucherov and Shelef on Fe/ZSM5 samples (obtained by sublimation) exceeding a $\mathrm{Fe} / \mathrm{Al}$ ratio of 0.6 [23]. Also the presence of weakly bound $\mathrm{FeCl}_{3}$ located on the external surface of the zeolite can not be ruled out [21].

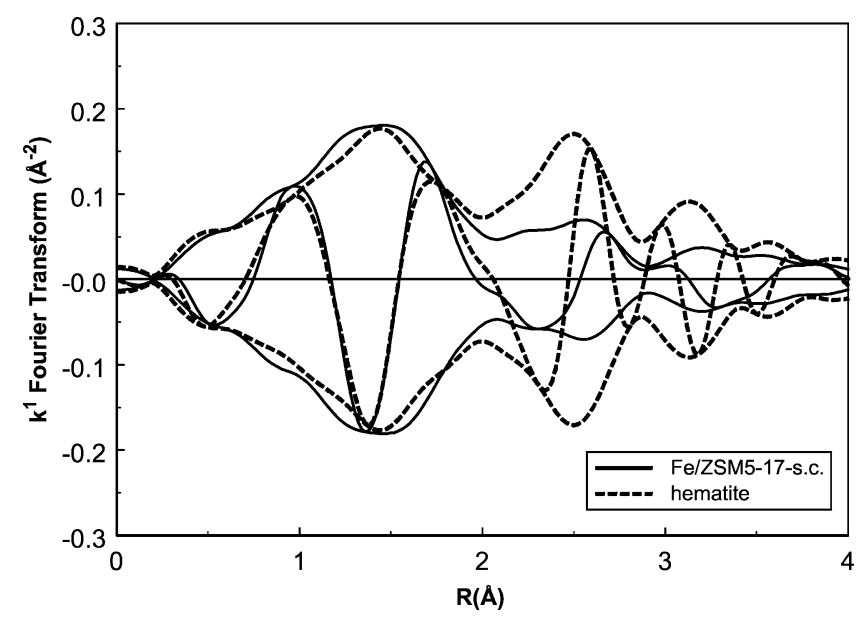

Fig. 16. $k^{1}$ Fourier transformed experimental EXAFS data of Fe/ZSM517 -sc and $\alpha-\mathrm{Fe}_{2} \mathrm{O}_{3}$, measured in $\mathrm{He}$ at $77 \mathrm{~K}(\Delta k=2.7-13.0)$. 


\subsection{Washing}

As already pointed out by Marturano et al. [21], washing was proved to be the key step for the formation of the binuclear Fe complexes, proposed as the catalytically active phase in Fe/ZSM5 [1,2,12,18]. It can be concluded from our work that during this step dramatic changes occur to the local environment of the Fe atoms. While the oxidation state of iron remained unchanged $\left(\mathrm{Fe}^{3+}\right)$, as appears from the centroid position of the HR-XANES Fe K pre-edge (Table 4) and from the near edge region of the XAFS spectra (Fig. 10), the geometry turned from tetrahedral to octahedral. Since the integrated intensity of the pre-edge peak of the Fe/ZSM5$17-\mathrm{H}_{2} \mathrm{O}$ sample is lower than that of the hematite reference, it is concluded that the octahedral configuration of iron in the Fe/ZSM5 after washing possesses a higher degree of symmetry than that in hematite [34]. The high dispersion of the Fe phase is underlined by the complete absence of pre-edge spectral contributions centered above $7115.0 \mathrm{eV}$. Their presence, reported in the literature to increase with the degree of $\mathrm{Fe}(\mathrm{O}, \mathrm{OH})_{6}$-octahedral polymerization (ferrihydrite $<$ goethite $<$ hematite) $[34,35]$, is, on the contrary, clearly visible in the pre-edge peak of the measured hematite (Figs. 8 and 9).

The removal of chlorine from the Fe local surrounding appeared clearly from the EXAFS results. The washing step must also be responsible for the displacement of part of the isolated mononuclear species and their subsequent restabilization to the $\mathrm{Al}$ of the framework to form Fe binuclear clusters. This observation is in agreement with the partial regain of the intensity of the Brønsted Al-OH vibrations (Fig. 1). From the IR it can also be deduced that the formed binuclear iron species are not bound at the silanols position, since the $\mathrm{Si}-\mathrm{OH}$ groups appeared to be completely restored after washing.

The Mössbauer spectra exclude the presence in our washed sample of a significant fraction of isolated monoatomic Fe species (Fig. 5a). The present of such species at this stage of the synthesis was suggested by Marturano et al. [21] in order to explain an EXAFS Fe-Fe coordination number lower than one (0.5) as found in the analysis of their EXAFS data. Our EXAFS data-analysis, on the contrary, shows a Fe-Fe coordination number of 1.0 (Table 5). The combination of the Mössbauer and EXAFS results obtained in this work proves that the coordination number of 1.0 found for the $\mathrm{Fe}-\mathrm{Fe}$ shell is not the result of an average between mononuclear Fe-species and Fe-polycations.

The Mössbauer result, on the other hand, suggest a possible underestimation in the coordination number of the $\mathrm{Fe}-\mathrm{Fe}_{1}$ shell obtained by the EXAFS fit. Indeed, some agglomeration of $\mathrm{Fe}$ was revealed by the Mössbauer spectrum collected from the washed Fe/ZSM5 sample at $4.2 \mathrm{~K}$ (Fig. 5a, Table 3a) [51]. The broad width of the sextet suggests the coexistence of Fe species with different nuclearity (average size of $2 \mathrm{~nm}$ ). Since no $\mathrm{Fe}-\mathrm{Fe}$ contribution could be fitted by EXAFS at high distances, typical of a three di-
Table 7

$\mathrm{Fe}-\mathrm{O}$ and $\mathrm{Fe}-\mathrm{Fe}$ atomic distances and coordination numbers in $\alpha$-goethite and hematite from X-ray diffraction data [58,59]

\begin{tabular}{|c|c|c|c|c|c|c|}
\hline \multirow[t]{3}{*}{ Shells } & \multirow{2}{*}{\multicolumn{2}{|c|}{$\begin{array}{c}\text { Closest } \mathrm{Fe}-\mathrm{Fe} \text { binuclear } \\
\text { unit in } \alpha \text {-goethite }\end{array}$}} & \multicolumn{2}{|c|}{$\alpha$-goethite } & \multicolumn{2}{|c|}{ Hematite } \\
\hline & & & \multirow{2}{*}{$R(\AA)$} & \multirow[t]{2}{*}{$\mathrm{CN}$} & \multirow[t]{2}{*}{$R(\AA)$} & \multirow[t]{2}{*}{$\mathrm{CN}$} \\
\hline & $R(\AA)$ & $\overline{\mathrm{CN}}$ & & & & \\
\hline $\mathrm{Fe}-\mathrm{O}_{1}$ & 1.95 & 3 & 1.95 & 3 & 1.96 & 3 \\
\hline $\mathrm{Fe}-\mathrm{O}_{2}$ & 2.09 & 3 & 2.09 & 3 & 2.12 & 3 \\
\hline $\mathrm{Fe}-\mathrm{Fe}_{1}$ & 3.02 & 1 & 3.02 & 2 & 2.95 & 4 \\
\hline $\mathrm{Fe}-\mathrm{Fe}_{2}$ & - & - & 3.28 & 2 & 3.36 & 3 \\
\hline $\mathrm{Fe}-\mathrm{Fe}_{3}$ & - & - & 3.46 & 4 & 3.74 & 7 \\
\hline
\end{tabular}

mensional polymerization [56,57], it is concluded that the agglomerated $\mathrm{Fe}$-containing phase must consist also of linear oligomers located in the zeolite micropores. The homogeneity of the distribution of iron within the zeolite crystals was confirmed by EELS (Figs. 3b and 4) and by HR-TEM (Fig. 2a). In particular, no gradient in the iron concentration was detected when approaching the crystal surface (note that the local concentration of iron measured by EELS was found to be consistent with the bulk ICP results) and no particles could be detected on the external surface of the zeolite.

The structure of the binuclear Fe complexes formed upon washing can be determined by comparing the $\mathrm{Fe}-\mathrm{O}$ and $\mathrm{Fe}-\mathrm{Fe}$ coordination numbers and interatomic distances in $\mathrm{Fe} / \mathrm{ZSM} 5-17-\mathrm{H}_{2} \mathrm{O}$ with those of $\alpha$-goethite and hematite, as obtained from XRD data [58,59] (see Table 7). As can be seen, the structural parameters obtained for Fe/ZSM5-17$\mathrm{H}_{2} \mathrm{O}$ with the $3: 3$ and the $2: 2: 2$ fit models (Table 5) correspond to those of the closest $\mathrm{Fe}-\mathrm{Fe}$ binuclear building block in $\alpha$-goethite. In this unit, two iron atoms are symmetrically connected via two hydroxyl groups.

The formation of highly dispersed binuclear complexes is coherent with the hydrolysis process known for $\mathrm{FeCl}_{3}$ in aqueous solution. This starts via the formation of a hexaaqua ion $\left[\left(\mathrm{Fe}\left(\mathrm{OH}_{2}\right)_{6}\right]^{3+}\right.$, which is stable only in strongly acidic media $\left(\left[\mathrm{H}^{+}>6 \mathrm{M}\right]\right)$ due to a strong tendency towards hydrolytic polymerization [56,57]. At higher $\mathrm{pH}$, a condition that is certainly encountered during the extensive washing of the zeolite, the formation of a dimer represents the first step prior to condensation to large polycations and possible precipitation as $\alpha$-goethite or hematite [56,57,60-62]. The extremely important role of the zeolitic support is indeed to prevent the thermodynamically favored iron condensation. This must be obtained by an immediate stabilization via the lattice charge of the nascent Fe binuclear complexes, which blocks their possible further migration and aggregation. A decisive role in this respect is most probably played also by the steric hindrance encountered by the iron species in the narrow micropores of the ZSM5. The question which still has to be answered is whether the zeolite is able to prevent further migration and polymerization of the Fe binuclear complexes also during the subsequent calcination step. 


\subsection{Calcination}

In order to investigate the stability of the Fe binuclear complexes two different calcination procedures were applied, i.e., a mild and a severe calcination. In both cases the final temperature $\left(550{ }^{\circ} \mathrm{C}\right)$ was maintained for three hours. While the severe calcination procedure reproduces conditions typical of a standard calcination, the mild calcination procedure was specially aimed to prevent metal clustering. A similar procedure was successfully applied by de Graaf et al. [63] in order to prevent agglomeration of Pt particles in zeolite Y. Mild calcination was obtained by coupling a high gas flow with a moderate temperature ramp. As a result, the highest possible quantity of moisture was removed from the zeolite at relatively low temperature, strongly suppressing the migration of hydrolyzed species and the resulting clustering.

Since the XRD patterns recorded after both types of calcination were identical to the one measured from the parent $\mathrm{H} /$ ZSM5 support, it is concluded that no damage occurred to the framework of the zeolite during these treatments. This observation is supported by the combination of the Al-XAFS and the Al-NMR results. Al-NMR showed that in the parent support around $93 \%$ of the $\mathrm{Al}$ atoms were arranged in tetrahedral coordination into the zeolite framework (Fig. 6). This result was confirmed by the Al K XANES data, recorded from the same support (Fig. 7). Since no differences were visible between the Al K XANES spectrum of H-ZSM5-17 and Fe/ZSM5-17-sc (Fig. 7), it is concluded that no large formation of extra-framework (octahedral) aluminum occurred during the synthesis, not even upon application of the most severe calcination procedure. No significant changes were visible in the IR spectra of the Fe/ZSM5 upon calcination as well (Fig. 1). The intensity of the silanol and of the Al Brønsted signal appeared to be similar to that of the washed sample. This indicates that, even after calcination, a significant fraction of iron was still bound to the zeolite framework. Nevertheless, differences in the broadening of the silanol and of the Al Brønsted bands make a quantitative comparison between washed and calcined samples not possible.

While the above mentioned results underline the stability of the support during the synthesis and the pretreatment of the Fe/ZSM5 catalysts, the effects of the different calcination procedures on the agglomeration of iron appear very clearly from the results of the macro- and microscopic characterization techniques. In the Mössbauer spectra of the severely calcined sample (Fig. 5c), sextet lines are visible at all temperatures. This is a clear indication of the presence of large particles with a size distribution from 2 to over $10 \mathrm{~nm}$. The presence of this sextet, on the contrary, appeared to be significantly lower when the mild calcination was applied (Fig. 5b). The fact that for mild calcination the onset of the magnetically split components occurred only at $77 \mathrm{~K}$ accounts for a significantly smaller average dimension of the agglomerated phase. Furthermore, the very large width of these asymmetrically broadened sextet lines reflects the poor crystallinity of the agglomerated phase after mild calcination.

The differences in the abundance, degree of crystallinity and dimension between the Fe-containing particles of the two samples was confirmed by TEM (Figs. $2 \mathrm{~b}-\mathrm{d}$ ). While on the severely calcined $\mathrm{Fe} / \mathrm{ZSM} 5 \mathrm{Fe}$-rich particles were easily detected (Fig. 2c), they were difficult to identify after mild calcination, even at the maximum possible magnification. On Fe/ZSM5-17-mc Fe particles were very low in number and degree of crystallinity, appearing as few and poorly defined darker spots. Their richness in iron was confirmed by local EDX elemental analysis. For the few visible Fe-containing crystals on the mildly calcined sample the best match of the $d$-spacings was obtained with crystalline $\alpha$-goethite and possibly hematite. On the severely calcined sample, together with $\alpha$-goethite, hematite crystals were clearly visible (see also Figs. 3e, 3f, and 4). This finding is coherent with the expected evolution of Fe metastable hydroxylated species. In the internal volume of the zeolite polymerization processes are hindered by both the unbalanced charge of the framework and the narrow dimensions of the zeolite pores. But, once iron is transported to the external surface, the agglomeration can proceed to the formation of the most thermodynamically stable structures, i.e., $\alpha$-goethite and, finally, hematite [56,57,60-62,64].

Part of iron was removed from the internal volume of the zeolites to the external surface after calcination. This was confirmed by the EELS measurements (Figs. 3d, 3f, and 4). While no significant change was measured in the micropore volume of the Fe/ZSM5 upon mild calcination, some regain in the internal volume was indeed detected after applying the severe procedure. The migration of iron towards the external surface of the crystals is clearly depicted in Fig. 3d. The edges of the crystal of the Fe/ZSM5-17-mc are clearly enriched in iron when compared to the internal region. Nevertheless, no clear aggregation in form of particles is detectable yet. On the severely calcined sample, on the other hand, large particles are visible.

The HR-XANES demonstrated that the oxidation state and the geometry of the local coordination of iron did not change upon calcination (Fig. 9, Table 4). Independently of the calcination procedure, $\mathrm{Fe}$ is present in octahedra with an oxidation state of $3+$. Some small tailing appeared in the Fe K-pre-edges after calcination at energies above $7115.0 \mathrm{eV}$. This contribution, which is more pronounced in the severely calcined sample, is ascribed to the presence of three-dimensional polymerization of part of iron $[34,35]$.

The Fourier transform of the EXAFS data of Fe/ZSM5 after mild calcination appears to be similar to that of the sample after washing (Fig. 15). This indicates that the agglomeration phenomena involved only a minor fraction of iron. An additional shell $\left(\downarrow \mathrm{Fe}-\mathrm{Fe}_{2}\right)$ with a low coordination number $(\mathrm{CN}=0.4)$ had to be introduced for optimizing the fitting of the $\mathrm{Fe}-\mathrm{Fe}$ scattering. Contemporarily, the $\mathrm{CN}$ of 
the first iron shell ( $\left.\downarrow \mathrm{Fe}-\mathrm{Fe}_{1}\right)$ appeared to be only slightly increased $(+20 \%)$ when compared to the sample measured after washing. The increase in the $\mathrm{Fe}-\mathrm{Fe}_{1}$ shell, whose distance is typical of edge-sharing octahedrally coordinated iron neighbors, can be ascribed to the additional formation of linear oligomers. As can be seen from Table 7 this shell $\left(\mathrm{Fe}-\mathrm{Fe}_{1}\right)$ is present in $\alpha$-goethite with a coordination number of 2. Also the distance of the second iron shell in Fe/ZSM5$17-\mathrm{mc}\left(\mathrm{Fe}-\mathrm{Fe}_{2}, 3.40 \AA\right)$ appears to match that obtained by the average of the external shells in $\alpha$-goethite $\left(\mathrm{Fe}-\mathrm{Fe}_{2}\right.$ and $\mathrm{Fe}-\mathrm{Fe}_{3}$ in Table 7). These shells are due to the presence in the goethite structure of corner sharing octahedrally coordinated $\mathrm{Fe}$ units. The appearance of this second shell in the Fourier transform of the mildly calcined Fe/ZSM5, therefore, can be attributed to the incipient formation of lowly agglomerated iron hydroxide particles, which can end up in the crystallization of $\alpha$-goethite particles. It should be noted that the results of the fit are coherent with the presence of $\alpha$-goethite crystallites revealed by HR-TEM. The small changes in coordination numbers of the $\mathrm{Fe}-\mathrm{Fe}$ shells, nevertheless, suggest that a significant fraction of iron must still exist in the form of binuclear complexes. From the coordination number of the $\mathrm{Fe}-\mathrm{Fe}$ shells (Table 6) binuclear clusters in $\mathrm{Fe} / \mathrm{ZSM} 5-17-\mathrm{mc}$ are estimated to account for around $70 \%$ of the total iron amount. It should be noted, nevertheless, that this value appears to be overestimated, when compared with the results obtained by Mössbauer spectroscopy (Table 3b), which reveals that after mild calcination binuclear complexes can not account for more than $40 \%$ of iron.

Much more clear changes were revealed in the EXAFS Fourier transform of the severely calcined sample (Fig. 15). The intensity of the two Fe-Fe shells appeared to be enhanced. This is reflected in the increment of the coordination numbers of both the $\mathrm{Fe}-\mathrm{Fe}_{1}$ and the $\mathrm{Fe}-\mathrm{Fe}_{2}$ shell to respectively 1.6 and 1.3 (Table 6). This simultaneous increase is the result of the formation of large $\alpha$-goethite and hematite crystals, as was indeed detected by HR-TEM and EELS. These particles were formed at the expense of iron located in the zeolite channels. From the EXAFS fit the amount of binuclear Fe-clusters after the severe calcination is estimated to be around $40 \%$ of the total iron quantity. As can be seen in Fig. 16 the $k^{1}$ Fourier transform of the Fe/ZSM5-17-sc is still very different from that of the hematite reference. This is ascribed to the very broad distribution in particle size and in the low degree of crystallinity of the aggregated phases. Also for this sample a lower presence of Fe binuclear species, when compared to the EXAFS results, is suggested by Mössbauer spectroscopy (less than $20 \%$ of iron).

While clear changes were revealed by EXAFS in the $\mathrm{Fe}-\mathrm{Fe}$ coordination of the $\mathrm{Fe} / \mathrm{ZSM} 5$ as a function of the calcination procedure, the $\mathrm{Fe}-\mathrm{O}$ coordination remained unchanged (Table 6). This result underlines the similarity, under the experimental conditions applied, in the oxygen distribution around iron in the Fe binuclear complexes (prior to and after calcination) and in the building blocks of

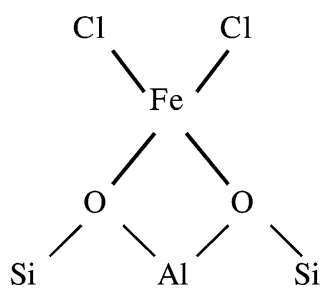

(a)

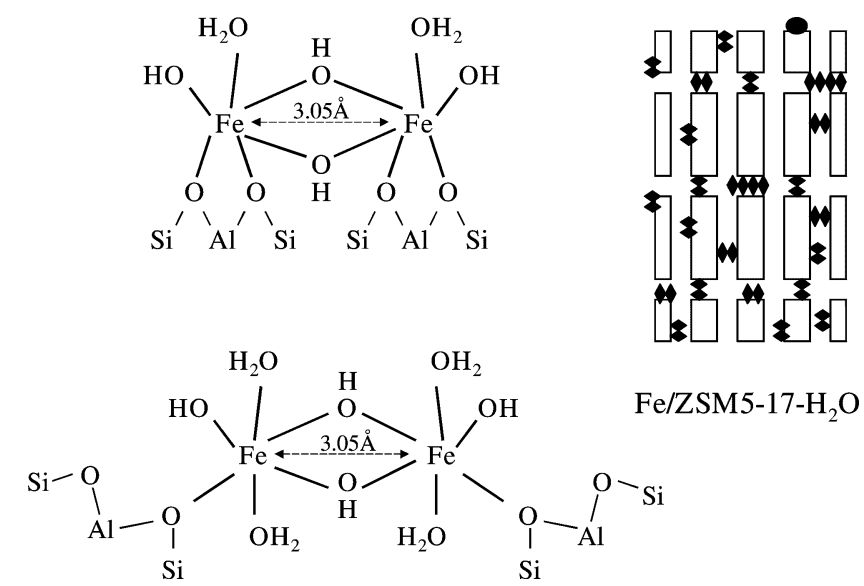

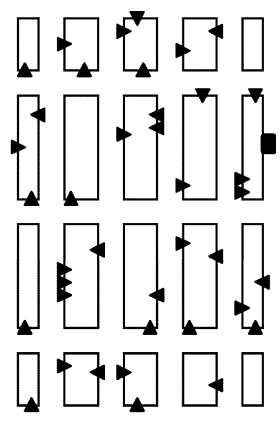

Fe/ZSM5-17-Cl (b)

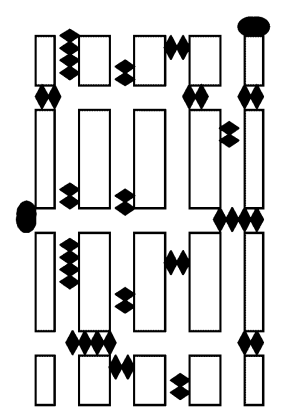

Fe/ZSM5-17-m.c.

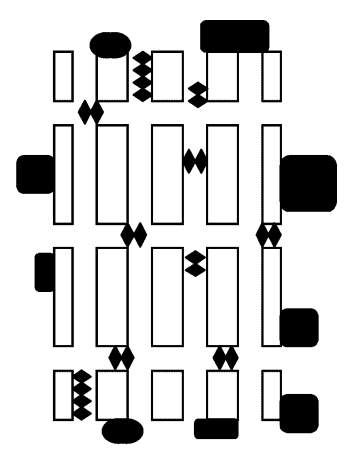

Fe/ZSM5-17-s.c. (c)

Fig. 17. Fe species in overexchanged Fe/ZSM5 after: (a) $\mathrm{FeCl}_{3}$ sublimation: Fe monomers at Al-Brønsted sites position ( $\mathbf{\nabla}$, see proposed structure); minor presence of Fe linear oligomers $(\boldsymbol{\nabla \nabla \nabla})$ and/or $\mathrm{FeCl}_{3}(\square)$; (b) washing: binuclear Fe oxo/hydroxo complexes $(\boldsymbol{W}$, see proposed structures); minor presence of linear Fe oxo/hydroxo oligomers (W) and amorphous Fe nanoparticles (O); (c) different calcination procedures. After mild calcination (left): binuclear $\mathrm{Fe}$ oxo/hydroxo complexes (W); linear $\mathrm{Fe}$ oxo/hydroxo oligomers (WW); amorphous Fe nanoparticles and infrequent goethite (possibly also hematite) crystallites $(-$ ); severe calcination (right): hematite and $\alpha$-goethite crystals ; Fe amorphous nanoparticles (O); linear Fe oxo/hydroxo oligomers (W); binuclear Fe oxo/hydroxo complexes (W). 
the agglomerated phase. All the Fe/ZSM5 samples (with the exception of the $\mathrm{Fe} / \mathrm{ZSM} 5-17-\mathrm{Cl}$ ) were pretreated with $\mathrm{He}$ at $30{ }^{\circ} \mathrm{C}$ after being exposed to air. Humidity could have been responsible for rehydration of the Fe binuclear complexes in the calcined Fe/ZSM5, veiling differences with the washed sample. This could be the reason for the differences between the results obtained in this study and those presented on the calcined Fe/ZSM5 by Marturano et al. [21]. In their EXAFS study a calcined Fe/ZSM5 sample was measured after flushing $\mathrm{He}$ at $400{ }^{\circ} \mathrm{C}$. The reactivity of oxygen in $\mathrm{Fe} / \mathrm{ZSM} 5$ will be discussed by our group in detail elsewhere [65].

It should be noted that the results of the EXAFS fitting presented in this work for the sample Fe/ZSM5-17-sc (Table 6) are different from those presented by our group on the same sample in a previous report [19]. Significant differences are present in the results of the fitting of both the $\mathrm{Fe}-\mathrm{O}$ and the $\mathrm{Fe}-\mathrm{Fe}$ contributions. The high-resolution XANES data of the severely calcined samples used in this study prove that under ambient conditions the local coordination of $\mathrm{Fe}$ is octahedral. The tetrahedral geometry found in the previous study could be the result of dehydration phenomena occurring during the pretreatment applied to $\mathrm{Fe} / \mathrm{ZSM} 5$ samples prior to the XAFS measurement $\left(\mathrm{He}, 150{ }^{\circ} \mathrm{C}\right.$ [19] versus $\mathrm{He}, 30^{\circ} \mathrm{C}$ (in this study). The differences in the $\mathrm{Fe}-\mathrm{Fe}$ fit, on the other hand, is clearly due to the underestimated $R$ fit range $R=1.0-3.0 \AA$ used in the previous study. As a consequence, the contribution of more distant iron, indeed present in the Fourier transformed signal at $3.2 \AA$, was overlooked. In this study the significantly improved quality of the EXAFS data allowed statistically more reliable fits in a wider $R$ range $1.0-4.0 \AA$ by using up to five different shells.

The results presented in this study are summarized in a scheme presented in Figs. 17a-c. The scheme combines the evolution along the synthesis of the Fe species, with a description of the migration and agglomeration phenomena occurring to iron at a macroscopic scale.

\section{Conclusions}

After $\mathrm{FeCl}_{3} \mathrm{CVD}$ iron is stabilized by the ZSM5 matrix in the form of isolated mononuclear complexes located at the Brønsted sites position. These iron complexes consist of tetrahedrally coordinated $\mathrm{Fe}^{3+}$ bound to the framework via two oxygens and further surrounded by two chlorine atoms. The presence at this stage of a minor fraction of binuclear chlorinated $\mathrm{Fe}$-complexes or $\mathrm{Fe}$ species with a higher nuclearity is suggested by EXAFS.

During the washing treatment mononuclear iron species are displaced and subsequently stabilized to the framework in the form of octahedrally coordinated binuclear Fe-complexes. The structure of the binuclear complexes, determined by EXAFS, resembles very closely that of the closest binuclear building blocks in $\alpha$-goethite, i.e., they consist of two edge-sharing octahedrally coordinated $\mathrm{Fe}$ atoms. The presence, after washing, of monomeric Fe species is ruled out.

As expected, calcination results in aggregation of iron, removed from the Brønsted sites. Applying a severe calcination results in significant migration of iron to the external surface of the zeolite, where if further aggregates to form abundant and clearly visible $\alpha$-goethite and hematite crystals. Oligomers and amorphous nano-particles are also formed within the zeolite micropores. The extent of this aggregation can nevertheless be limited by adequately tuning the conditions of the calcination.

\section{Acknowledgments}

We kindly thank N. Haack and M. Hermann, (station X1.1 at Hasylab, Hamburg), C. Henriquet (station ID16 at ESRF, Grenoble), and A. Smith (station 3.4 at the SRS, Daresbury) for their help during the X-ray Absorption measurements.

The NMR facility at Nijmegen University, The Netherlands, is kindly thanked for providing magnet measurement time. H. Schaefer is thanked for his help during the measurements.

The European Union program for Large Scale Facilities (ERBFMGECT950059) and NWO (326-710) are acknowledged for financial support.

\section{References}

[1] H.-Y. Chen, W.M.H. Sachtler, Catal. Today 42 (1998) 73.

[2] H.-Y. Chen, T. Voskoboinikov, W.M.H. Sachtler, J. Catal. 180 (1998) 171.

[3] H.-Y. Chen, T. Voskoboinikov, W.M.H. Sachtler, Catal. Today 54 (1999) 483.

[4] R.Q. Long, R.T. Yang, J. Am. Chem. Soc. 121 (1999) 5595.

[5] A.-Z. Ma, W. Grünert, Chem. Commun. (1999) 71.

[6] Q. Sun, Z.-H. Gao, H.-Y. Chen, W.M.H. Sachtler, J. Catal. 201 (2001) 89.

[7] E.-M. El-Malki, R.A. van Santen, W.M.H. Sachtler, J. Catal. 196 (2000) 212.

[8] X. Feng, W.K. Hall, J. Catal. 166 (1997) 368.

[9] M. Kögel, V.H. Sandoval, W. Schwieger, A. Tissler, T. Turek, Catal. Lett. 51 (1998) 23.

[10] R. Joyner, M. Stockenhuber, J. Phys. Chem. B 103 (1999) 5963.

[11] L.J. Lobree, I.-C. Hwang, J.A. Reimer, A.T. Bell, J. Catal. 186 (1999) 242.

[12] E.-M. El-Malki, R.A. van Santen, W.M.H. Sachtler, J. Catal. 196 (2000) 212.

[13] F. Heinrich, C. Schmidt, E. Löffler, W. Grünert, Catal. Comm. 2 (2001) 317.

[14] M. Kögel, R. Mönnig, W. Schwieger, A. Tissler, T. Turek, J. Catal. 182 (1999) 470.

[15] M. Rauscher, K. Kesore, R. Mönnig, W. Schwieger, A. Tißler, T. Turek, Appl. Catal. A 184 (1999) 249.

[16] W.K. Hall, X. Feng, J. Dumesic, R. Watwe, Catal. Lett. 52 (1998) 13.

[17] P. Marturano, A. Kogelbauer, R. Prins, J. Catal. 190 (2000) 460.

[18] H.-Y. Chen, E.-M. El-Malki, X. Wang, R.A. van Santen, W.M.H. Sachtler, J. Molec. Catal. A 162 (2000) 159. 
[19] A.A. Battiston, J.H. Bitter, D.C. Koningsberger, Catal. Lett. 66 (2000) 75.

[20] P. Marturano, L. Drozdová, A. Kogelbauer, R. Prins, J. Catal. 192 (2000) 236.

[21] P. Marturano, L. Drozdová, G.D. Pirngruber, A. Kogelbauer, R. Prins, Phys. Chem. Chem. Phys. 3 (2001) 5585.

[22] T. Voskoboinikov, H.-Y. Chen, W.M.H. Sachtler, J. Molec. Catal. A 155 (2000) 155.

[23] A.V. Kucherov, M. Shelef, J. Catal. 195 (2000) 106.

[24] C. Jeanguillaume, C. Colliex, Ultramicroscopy 28 (1989) 252.

[25] C. Colliex, M. Tencé, E. Lefèvre, C. Mory, H. Gu, D. Bouchet, C. Jeanguillaume, Mikrochim. Acta 71 (1994) 114.

[26] J.A. van Bokhoven, H. Sambe, D.E. Ramaker, D.C. Koningsberger, J. Phys. Chem. B 103 (36) (1999) 7557.

[27] J.A. van Bokhoven, A.M.J. van der Eerden, A.D. Smith, D.C. Koningsberger, J. Synchrotron Rad. 6 (1999) 201.

[28] A.M.J. van der Eerden, J.A. van Bokhoven, A. Smith, D.C. Koningsberger, Rev. Sci. Instrum. 71 (9) (2000) 3260.

[29] F. Sette, G. Ruocco, M. Krisch, U. Bergmann, C. Masciovecchio, V. Mazzacurati, G. Signorelli, R. Verbeni, Phys. Rev. Lett. 75 (1995) 850.

[30] K. Hämäläinen, D.P. Siddons, J.B. Hastings, L.E. Berman, Phys. Rev. Lett. 67 (1991) 2850.

[31] F.M.F. de Groot, S. Pizzini, A. Fontaine, K. Hämäläinen, C.C. Kao, J.B. Hastings, Phys. Rev. B 51 (1995) 1045.

[32] M. Vaarkamp, B.L. Mojet, F.S. Modica, J.T. Miller, D.C. Koningsberger, J. Phys. Chem. 99 (1995) 16067.

[33] S.L.M. Schroeder, Adv. Spectroscopy 26 (1998) 1.

[34] M. Wilke, F. Farges, P.-E. Petit, G.E. Brown Jr., F. Martin, Am. Miner. 86 (2001) 714.

[35] G. Dräger, R. Frahm, G. Materlik, O. Brummer, Phys. Stat. Sol. B 146 (1988) 287.

[36] M. Vaarkamp, J.C. Linders, D.C. Koningsberger, Physica B 209 (1995).

[37] M. Vaarkamp, I. Dring, R.J. Oldman, E.A. Stern, D.C. Koningsberger, Phys. Rev. B 50 (1994) 7872.

[38] D.C. Koningsberger, B.L. Mojet, G.E. van Dorssen, D.E. Ramaker, Top. Catal. 10 (2000) 143.

[39] J.W. Cook, D.E. Sayers, J. Appl. Phys. 52 (1981) 5024.

[40] J. Iball, C.H. Morgan, Acta Cryst. 23 (1967) 239.

[41] A.L. Ankudinov, J.J. Rehr, Phys. Rev. B 56 (1997) R1712.
[42] R.L. Blake, R.E. Hessevick, T. Zoltai, L.W. Finger, Am. Miner. 51 (1966) 123.

[43] M.D. Lind, J. Chem. Phys. 47 (3) (1967) 990.

[44] D.C. Koningsberger, Jpn. J. Appl. Phys. 32 (1993) 877.

[45] G.G. Li, F. Bridges, C.H. Booth, Phys. Rev. B 52 (1995) 6332.

[46] S. Bordiga, E.E. Platero, C.O. Arean, C. Lamberti, A. Zecchina, J. Catal. 137 (1992) 179.

[47] G.L. Woolery, L.B. Alemany, R.M. Dessau, A.W. Chesler, Zeolites 6 (1986) 14.

[48] L.M. Kustov, V.B. Kazansky, S. Beran, L. Kubelkova, P. Jiru, J. Phys. Chem. 91 (1987) 5247.

[49] A. Zecchina, S. Bordiga, G. Spoto, D. Scarano, D. Petrini, G. Leofanti, M. Padovan, C.J. Otero Areàn, J. Chem. Soc. Faraday Trans. 88 (1992) 2959.

[50] Powder Diffraction File 2000, International Centre for Diffraction data, USA, 2000.

[51] S. Mørup, Hyperfine Interactions 60 (1990) 959.

[52] G. Engelhardt, D. Michel, High-Resolution Solid-State NMR of Silicates and Zeolites, Wiley, New York, 1987.

[53] E. Bourgeat-Lami, P. Massiani, F. Di Renzo, P. Espiau, F. Fajula, T. Des Courières, Appl. Catal. 72 (1991) 139.

[54] D. Heumann, G. Dräger, S. Bocharov, J. Physique IV 7C2 (1997) 481.

[55] T.E. Westre, P. Kennepohl, J. de Witt, B. Hedman, K.O. Hogson, E.I. Solomon, J. Am. Chem. Soc. 119 (1997) 6297.

[56] D.T. Richens, The Chemistry of Aqua Ions, Wiley, New York, 1997.

[57] J.-P. Jolivet, Metal Oxide Chemistry and Synthesis, Wiley, New York, 2000.

[58] S. Suzuki, T. Suzuki, M. Kimura, Y. Takagi, K. Shinoda, K. Tohji, Y. Waseda, Appl. Surf. Science 169-170 (2001) 109.

[59] J.R. Rustad, A.R. Felmy, B.P. Hay, Geochim. Cosmochim. Acta 90 (1996) 1553.

[60] R.N. Sylva, Pure. Appl. Chem. 22 (1972) 115.

[61] C.M. Flynn, Chem. Rev. 84 (1984) 31.

[62] L.M. Cornell, R. Giovanoli, W. Schneider, J. Chem. Tech. Biotechnol. 46 (1989) 115.

[63] J. de Graaf, A.J. van Dillen, K.P. de Jong, D.C. Koningsberger, J. Catal. 203 (2001) 307

[64] S. Musíc, I. Czakó-Nagy, I. Salaj-Obelic, N. Ljubešic, Mater. Lett. 32 (1997) 301.

[65] A.A. Battiston, J.H. Bitter, W.M. Heijboer, F.M.F. de Groot, D.C. Koningsberger, J. Catal., submitted. 